\title{
EFFECT OF HEAT TRANSFER COEFFICIENT, DRAW RATIO AND \\ DIE EXIT TEMPERATURE ON THE PRODUCTION OF FLAT \\ POLYPROPYLENE MEMBRANES
}

\author{
Tomas Barborik, Martin Zatloukal* \\ Polymer Centre, Faculty of Technology, Tomas Bata University in Zlin, \\ Vavreckova 275, 76001 Zlin, Czech Republic
}

Keywords: Flat film production, polymer melt, rheology, neck-in phenomenon, heat transfer, crystallization, linear isotactic polypropylene.

*Corresponding author: mzatloukal@utb.cz 


\begin{abstract}
In this work, stable numerical scheme has been developed for 1.5-dimensional film casting model of Silagy et al. (Polym Eng Sci 36:2614-2625, 1996) utilizing viscoelastic modified Leonov model as the constitutive equation and energy equation coupled with crystallization kinetics of semicrystalline polymers taking into account actual temperature as well as cooling rate. The model has been successfully validated on the experimental data for linear isotactic polypropylene taken from the open literature. Drawing distance, draw ratio, heat transfer coefficient and die exit melt temperature were systematically varied in the utilized model in order to understand the role of process conditions on the neck-in phenomenon (unwanted film width shrinkage during stretching in the post die area) and crystalline phase development during flat film production. It is believed that the utilized numerical model together with suggested stable numerical scheme as well as obtained research results can help to understand a processing window for the production of flat porous membranes from linear polypropylene considerably.
\end{abstract}




\section{INTRODUCTION}

For the production of transparent packaging materials via a cast film process, high demands are required on the optical properties of the manufactured thin films, which can be achieved by the use of wide extrusion dies, very high processing temperatures and short stretching distances minimizing the neck-in phenomenon and related dog-bone defect. The film cooling is not sufficient and the temperature field is rather uniform in this spatial configuration. It was shown in early studies devoted to the heat transfer in film casting, [1-3] and [4] (measured temperature drop by IR camera was less than $15^{\circ} \mathrm{C}$ ), that such flows can be viewed as the isothermal. On the other hand, if the stretching distance increases too much, the film temperature decreases, melt viscosity increases and temperature and/or stress induced crystallization may start to occur, which can influence the process considerably. Effect of the temperature in film casting [5] has been experimentally investigated for polyethylene terephthalate (PET) polymer using the infrared thermography apparatus with the capability to measure the temperature variation in the film width and axial direction (machine direction). It was concluded that the temperature variations should be accounted for geometries with a large die width and take-up length greater than $1 / 10$ of die width.

There are two contradictory practices of setting up the processing conditions depending on whether the final film is to be used for packaging or membrane applications. Thin films for wrapping/packaging should possess a transparency with low haze and high clarity whereas precursor films for microporous membrane should contain a crystalline phase. The development of a crystalline phase in semi-crystalline polymers is strongly influenced by applied processing conditions, when under quiescent isothermal conditions of crystallization, the kinetics is a function of temperature whilst in a quiescent non-isothermal case, additionally, a rate of cooling comes into play [6]. This is especially encountered during fabrication of porous membranes where high cooling rates are often applied. 
A great amount of research effort on the crystallization and flow-induced crystallization in the film casting process has been done by a group of Titomanlio and Lamberti $[7,8,17,9-16]$. Very early crystallization models [18-20] were developed for metal materials under the constant temperature, that is, a crystallization rate and thermal history is not linked together. Next step in the model development was an introduction of Kolmogoroff-Avrami-Evans equation describing the evolution of a crystalline phase through the time [19, 21-23]. Further works [24, 25] and [26] used an isokinetic hypothesis which accounts for a proportionality between a crystal nucleation and its growth rate. A quite simple determination of the model parameters via differential scanning calorimetry (DSC), i.e. not requiring any special apparatus, can be considered as a benefit of this approach. More recently, Ziabicki has introduced a model, which includes the transient and non-isothermal effects [27, 28].

The experimental investigation of crystallization during fast-cooling experiments was carried out $[29,30]$ usually by means of DSC or by using fast scanning chip calorimetry, FSC, allowing to reach cooling rates in order of thousands of K/s [31]. For polypropylene (PP), it has been shown that a high chain orientation in the melt state can lead to a production of row nucleated lamellar structure [32].

Isotactic polypropylene (iPP) is a significant commercial thermoplastic polymer with various industrial applications and can be considered as a good candidate for a gas separation, filtration, medical application, air-permeable membranes in an advanced apparel.

In the last decades, polypropylene microporous membranes are broadly applied in the industry for Lithium-ion batteries in the form of separators to keep electrodes away from each other (avoidance of electrical short circuit) as well as to simultaneously allow a transportation of ionic charge carriers [33-35]. PP has certain superior properties that favors it over polyethylene for such a use as excellent dimensional stability at high temperatures, high melting temperature, higher chemical resistance and good mechanical properties. Isotactic 
polypropylene and its inherited polymorphism enables a crystallization into different crystal modifications during a solidification depending on the cooling conditions [36-38].

Polypropylene membranes are usually fabricated by the thermal-induced phase separation, non-solvent-induced phase separation (using e.g. mineral fillers) and a dry process based on melt-stretching mechanism. In particular, the latter method, so-called MEAUS (melt extrusion-annealing-uniaxial stretching) technology, possesses an advantage of lower expenses and environmental pollution footprint since the use of solvents may be avoided.

The fabrication process of membranes based on the melt-stretching approach can be applicable for semi-crystalline polymers and distinguished into three major consecutive stages: first, a precursor film with a lamellar crystalline structure is produced; second, the film is annealed to thicken lamellae and obliterate the defects of crystalline phase (an improved uniformity and lamellae orientation through melting and recrystallization [39]); third, stretching is applied upon the film at a low and high temperature to create voids due to lamellae separation and enlarge them into the microporous structure, respectively. To keep good dimensional stability over time and lower the shrinkage of the produced microporous membranes, an additional treatment step of heat setting [40] is usually included. During the first stage, the polymer characteristics and extrusion processing conditions are important in generation of a row-nucleated lamellar structure [41]. The polymer architecture, molecular weight and molecular weight distribution seem to be the key material characteristics responsible for the formation of an appropriate crystalline microstructure [39, 42-45] as a necessary presumption for creation of stretching-generated pores with even spatial distribution and suitable size. For the cast film processing conditions, it has been reported [46] that the increase in draw ratio and severe cooling conditions at the area of die exit have a significant effect on the crystal orientation. Further research was conducted for much lower chill roll temperatures and different die temperatures [47]. 
Investigation of a crystallization development/flow-induced crystallization by means of the simultaneous modelling with process kinematic equations has already been conducted in the field of fiber spinning process [48-56]; however, to our best knowledge, only sparse attention has been paid for the film casting process. Thus, it is not surprising that a processing window for the production of porous membranes, flow stability and the role of process parameters are not fully understood yet. In order to fill this knowledge gap, the novel viscoelastic film casting model utilizing 1.5 dimensional (1.5D) membrane approximation [57], modified Leonov model as the constitutive equation $[58,59]$ and energy equation coupled with advanced crystallization kinetics $[27,28,60]$ was derived, validated and consequently used in the detailed parametric study. 


\section{MATHEMATICAL MODELLING}

\subsection{Film casting model}

To determine basic process variables in deformation flow with a free surface in the post die area, the one-dimensional membrane model [57] for extrusion film casting was employed and numerically solved. Even though the dimensionality of the model is unity, it possesses the capability to predict both, the reduction in film thickness as well as film width shrinkage owning to assumed flow kinematics [61]. From this point of view, the model might be considered as a pseudo 2D or 1.5D and principal velocities (see Figure 1) are allowed to be varied along the axial direction as follows

$$
\begin{aligned}
& \mathrm{u}=\mathrm{u}(\mathrm{x}) \\
& \mathrm{v}=\mathrm{v}(\mathrm{x}, \mathrm{y})=\mathrm{yf}(\mathrm{x}) \\
& \mathrm{w}=\mathrm{w}(\mathrm{x}, \mathrm{z})=\mathrm{zg}(\mathrm{x})
\end{aligned}
$$

Here, velocity in axial, transversal and thickness direction is denoted as $u, v$ and $w$, respectively. The membrane model comprises of governing equations for the continuity and momentum conservation that are simultaneously solved with the equation of energy and viscoelastic single-mode modified Leonov model as the constitutive equation.

\subsection{Constitutive equation}

The utilized modified Leonov model is based on heuristic thermodynamic arguments resulting from the theory of rubber elasticity $[58,62-66]$. In this constitutive equation, a fading memory of the melt is determined through an irreversible dissipation process driven by the dissipation term, $b$. 
From a mathematical viewpoint, it is relating the stress and elastic strain stored in the material as:

$$
\stackrel{\tau}{=}=2\left(\stackrel{\mathrm{c}}{=} \cdot \frac{\partial \mathrm{W}}{\partial \mathrm{I}_{1, \mathrm{c}}}-\stackrel{\mathrm{c}}{-1}^{-1} \cdot \frac{\partial \mathrm{W}}{\partial \mathbf{I}_{2, \mathrm{c}}}\right)
$$

where $\underset{\underline{\tau}}{\underline{ }}$ is the stress, and $W$, the elastic potential, which depends on the invariants $I_{1, c}$ and $I_{2, c}$ of the recoverable Finger tensor $\underline{\underline{c}}$,

$$
\mathrm{W}=\frac{3 \mathrm{G}}{2(\mathrm{n}+1)}\left\{[1-\beta] \cdot\left[\left(\frac{\mathrm{I}_{1, \mathrm{c}}}{3}\right)^{\mathrm{n}+1}-1\right]+\beta\left[\left(\frac{\mathrm{I}_{2, \mathrm{c}}}{3}\right)^{\mathrm{n}+1}-1\right]\right\}
$$

where $G$ denotes a linear Hookean elastic modulus, $\beta$ and $n$ are numerical parameters. Leonov assumed that the dissipative process acts to produce an irreversible rate of strain $\underline{e}_{p}$

$$
\stackrel{\mathrm{e}}{\mathrm{p}}_{\mathrm{p}}=\mathrm{b}\left[\underline{\underline{\mathrm{c}}}-\frac{\mathrm{I}_{1, \mathrm{c}}}{3} \underline{\underline{\delta}}\right]-\mathrm{b}\left[\underline{\mathrm{c}}^{-1}-\frac{\mathrm{I}_{2, \mathrm{c}}}{3} \underline{\underline{\delta}}\right]
$$

which spontaneously reduces the rate of elastic strain accumulation. Here, $\underline{\underline{\delta}}$ is the unit tensor and $b$ stands for dissipation function defined by Eq. 7. This elastic strain $\underline{c}$ is related to the deformation rate tensor $\underline{\underline{D}}$ as follows

$$
\stackrel{\stackrel{\mathrm{c}}{=}}{\underline{\mathrm{c}}} \cdot \underline{\underline{\mathrm{D}}}-\underline{\underline{\mathrm{D}}} \cdot \stackrel{\mathrm{c}}{=}+2 \stackrel{\mathrm{c}}{=} \cdot \underline{\mathrm{e}}=0
$$

where $\underline{\underline{c}}$ is the Jaumann (corotational) time derivative of the recoverable Finger strain tensor. The process-specific deformation rate tensor takes the following form and contains only diagonal terms considering an extensional nature of the flow situation in the air gap.

$$
\underline{\underline{D}}=\left(\begin{array}{ccc}
\mathrm{du} / \mathrm{dx} & 0 & 0 \\
0 & \mathrm{f}(\mathrm{x}) & 0 \\
0 & 0 & \mathrm{~g}(\mathrm{x})
\end{array}\right)
$$


In this work, the Mooney potential (i.e. $\mathrm{n}=0$ in Eq. 3), and the dissipation function $b$ proposed in [59] (see Eq. 7) have been employed.

$$
\mathrm{b}\left(\mathrm{I}_{1, \mathrm{c}}\right)=\frac{1}{4 \lambda}\left\{\exp \left[-\xi \sqrt{\mathrm{I}_{1, \mathrm{c}}-3}\right]+\frac{\sinh \left[v\left(\mathrm{I}_{1, \mathrm{c}}-3\right)\right]}{v\left(\mathrm{I}_{1, \mathrm{c}}-3\right)+1}\right\}
$$

Here, $\xi$ and $v$ are temperature independent adjustable model parameters and $\lambda$ is the relaxation time.

\subsection{Continuity and momentum conservation equations}

The essential model equations in this section were transformed to the dimensionless form with the following convention and in accordance with the open literature [57]: the zero subscript and overbar sign denote initial (at the die values) and dimensionless corresponding quantity, respectively. Then, the dimensionless component $i i$ of the extra stress tensor $\bar{\tau}_{i i}$ writes

$$
\bar{\tau}_{\mathrm{ii}}=\frac{\tau_{\mathrm{ii}} \mathrm{e}_{0} \mathrm{~L}_{0}}{\mathrm{~F}}
$$

where $F$ is drawing force exerted onto film, $e_{0}$ and $L_{0}$ are half-width and half-thickness of the film at the die, respectively.

Another set of dimensionless numbers is related to the film dimensions and velocities.

$$
\overline{\mathrm{x}}=\frac{\mathrm{x}}{\mathrm{X}} ; \quad \overline{\mathrm{e}}=\frac{\mathrm{e}}{\mathrm{e}_{0}} ; \quad \overline{\mathrm{L}}=\frac{\mathrm{L}}{\mathrm{L}_{0}} ; \quad \overline{\mathrm{u}}=\frac{\mathrm{u}}{\mathrm{u}_{0}}
$$

Where, $x$ is the actual axial position in the air gap, $X$ is the length of the air gap and $u$ is the axial velocity of the film. Further dimensionless numbers express the intensity of film drawing as draw ratio, $D R$, melt elasticity as Deborah number, $D e$, basic geometry of the process as aspect ratio, $A$, and dimensionless drawing force as $E$. 


$$
\mathrm{DR}=\frac{\mathrm{u}(\mathrm{X})}{\mathrm{u}_{0}} ; \quad \mathrm{De}=\frac{\lambda \mathrm{u}_{0}}{\mathrm{X}} ; \quad \mathrm{A}=\frac{\mathrm{X}}{\mathrm{L}_{0}} ; \quad \frac{1}{\mathrm{E}}=\frac{\mathrm{FX}}{\mathrm{G} \lambda \mathrm{e}_{0} \mathrm{~L}_{0} \mathrm{u}_{0}}
$$

Here, melt relaxation time and elastic modulus, both at the die, is denoted as $\lambda$ and $G$, respectively.

Then, the conservation of mass under the assumption of melt incompressibility in any position within the drawing distance must comply following formula

$$
\overline{\mathrm{e}} \overline{\mathrm{L}} \overline{\mathrm{u}}=1
$$

Considering the membrane approximation for a thin film in the presence of a constant drawing force, the momentum conservation equation yields

$$
\left(\bar{\tau}_{\mathrm{xx}}-\bar{\tau}_{\mathrm{zz}}\right)-\overline{\mathrm{u}}=0
$$

Making use of the kinematic free-surface and stress-free surface boundary condition, the unknown functions in Eq. 1. (i.e. $f(x)$ and $g(x)$ ) can be determined and the film width-stress relationship at given dimensionless axial position, $\bar{x}$, Eq. 13 deduced as

$$
\frac{\mathrm{d} \overline{\mathrm{L}}}{\mathrm{d} \overline{\mathrm{x}}}=-\mathrm{A} \sqrt{\frac{\bar{\tau}_{\mathrm{yy}}-\bar{\tau}_{\mathrm{zz}}}{\bar{\tau}_{\mathrm{xx}}-\bar{\tau}_{\mathrm{zz}}}}
$$

Differentiating Eqs. 11 and 12 with respect to $\bar{x}$ variable and after algebraic rearrangement, the derivative of the dimensionless film half-thickness with respect to $\bar{x}$ leads to

$$
\frac{\mathrm{d} \overline{\mathrm{e}}}{\mathrm{d} \overline{\mathrm{x}}}=-\left(\frac{1}{\overline{\mathrm{L}}} \frac{\mathrm{d} \overline{\mathrm{L}}}{\mathrm{d} \overline{\mathrm{x}}}+\frac{1}{\overline{\mathrm{u}}} \frac{\mathrm{d} \overline{\mathrm{u}}}{\mathrm{d} \overline{\mathrm{x}}}\right) \overline{\mathrm{e}}
$$

Utilization of Mooney potential in the modified Leonov model constitutive equation (i.e. when $\mathrm{n}=0$ and $\beta \neq 0$ in Eq. 3), the relationship between the dimensionless stress and recoverable strain takes the following form

$$
\bar{\tau}_{\mathrm{ii}}=\frac{\mathrm{E}}{\mathrm{De}} \mathrm{c}_{\mathrm{ii}}-\frac{\mathrm{E}}{\mathrm{De}} \mathrm{c}_{\mathrm{ii}} \cdot \beta-\frac{\mathrm{E}}{\mathrm{De}} \mathrm{c}_{\mathrm{ii}}^{-1} \cdot \beta
$$


To determine the diagonal components of the recoverable strain tensor, $c_{i i}$, and their derivatives with respect to $\bar{x}$, the membrane model and constitutive equations were linked together yielding following formulas

$$
\begin{aligned}
& \frac{d c_{x x}}{d \bar{x}}=2 c_{x x} \frac{1}{\bar{u}} \frac{d \bar{u}}{d \bar{x}}-\frac{2 \bar{b}}{\bar{u}} Z_{x} \\
& \frac{d c_{y y}}{d \bar{x}}=2 c_{y y} \frac{1}{\bar{L}} \frac{d \bar{L}}{d \bar{x}}-\frac{2 \bar{b}}{\bar{u}} Z_{y} \\
& \frac{d c_{z z}}{d \bar{x}}=2 c_{z z} \frac{1}{\bar{e}} \frac{d \bar{e}}{d \bar{x}}-\frac{2 \bar{b}}{\bar{u}} Z_{z}
\end{aligned}
$$

where the dimensionless dissipation function, $\bar{b}$, and $Z_{i}$ are defined as

$$
\begin{aligned}
& \bar{b}\left(I_{1, c}\right)=\frac{1}{4 D e}\left\{\exp \left[-\xi \sqrt{I_{1, c}-3}\right]+\frac{\sinh \left[v\left(I_{1, c}-3\right)\right]}{v\left(I_{1, c}-3\right)+1}\right\} \\
& Z_{i}=c_{i i}\left[c_{i i}-c_{i i}^{-1}+\frac{1}{3}\left(c_{x x}^{-1}+c_{y y}^{-1}+c_{z z}^{-1}-c_{x x}-c_{y y}-c_{z z}\right)\right]
\end{aligned}
$$

To complete the ensemble of equations, the express for dimensionless streamwise deformation rate is constituted by a combination of Eqs. 11, 12, and 15 as follows

$$
\frac{\mathrm{d} \overline{\mathrm{u}}}{\mathrm{d} \overline{\mathrm{x}}}=\frac{\overline{\mathrm{b}}\left[\beta\left(\mathrm{Z}_{\mathrm{x}}-\mathrm{Z}_{\mathrm{z}}\right)-\mathrm{Z}_{\mathrm{x}}+\mathrm{Z}_{\mathrm{z}}\right]+\overline{\mathrm{b}} \beta\left(\frac{1}{\mathrm{c}_{\mathrm{zz}}^{2}} \mathrm{Z}_{\mathrm{z}}-\frac{1}{\mathrm{c}_{\mathrm{xx}}^{2}} \mathrm{Z}_{\mathrm{x}}\right)+\frac{\overline{\mathrm{u}}}{\overline{\mathrm{L}}} \frac{\mathrm{d} \overline{\mathrm{L}}}{\mathrm{d} \overline{\mathrm{x}}}\left(\mathrm{c}_{\mathrm{zz}}(1-\beta)+\frac{\beta}{\mathrm{c}_{\mathrm{zz}}}\right)}{\beta\left(\mathrm{c}_{\mathrm{xx}}+\mathrm{c}_{\mathrm{zz}}\right)-\mathrm{c}_{\mathrm{xx}}-\mathrm{c}_{\mathrm{zz}}-\frac{\beta}{\mathrm{c}_{\mathrm{xx}}}\left(\frac{\mathrm{c}_{\mathrm{zz}}+\mathrm{c}_{\mathrm{xx}}}{\mathrm{c}_{\mathrm{zz}}}\right)+\frac{D e \overline{\mathrm{u}}}{2 \mathrm{E}}}
$$

Listed equations in this section, namely Eqs. 13, 14, 16, 17, 18, and 21, represent the basic isothermal viscoelastic $1.5 \mathrm{D}$ membrane model based on the constitutive equation of modified Leonov model and their more detail derivation can be found elsewhere [67]. In order to extend the model into a non-isothermal variant with the capability to predict crystallization, the energy equation with an appropriate crystallization kinetics has to be incorporated as described in the following paragraph. 


\subsection{Energy Equation}

The energy balance equation [7] takes the following form and accounts for the temperature change, crystallinity and flow dependency of melt viscosity.

$$
\frac{\mathrm{dT}}{\mathrm{dx}}=\frac{2 \mathrm{HTC}\left(\mathrm{T}_{\mathrm{a}}-\mathrm{T}\right) \mathrm{L}}{\mathrm{C}_{\mathrm{p}} \dot{\mathrm{m}}}+\frac{\Delta \mathrm{H}}{\mathrm{C}_{\mathrm{p}}} \frac{\mathrm{dX}}{\mathrm{dx}}
$$

where, the $L(x)$ is film half-width, $H T C$ is heat transfer coefficient, $C_{p}$ is specific heat capacity, $\dot{m}$ is mass flow rate in quarter-cross-section, $\Delta H$ is latent heat of crystallization, $T(x)$ and $T_{a}$ is melt and ambient air temperature, respectively, and finally $X_{c}(x)$ stands for content of crystallinity in the polymer volume. Heat transfer coefficient was chosen to be a constant for the current study as a simplification representing a total heat exchange with the surrounding environment. The temperature dependence of the melt relaxation time, $\lambda$, is described by Arrhenius form with a constant activation energy $E_{a}$ as follows

$$
\begin{gathered}
\lambda=\alpha_{\mathrm{T}} \lambda_{0} \\
\alpha_{\mathrm{T}}=\exp \left[\frac{\mathrm{E}_{\mathrm{a}}}{\mathrm{R}}\left(\frac{1}{\mathrm{~T}}-\frac{1}{\mathrm{~T}_{\mathrm{r}}}\right)\right]
\end{gathered}
$$

where $\lambda_{0}$ denotes the melt relaxation time at the die exit, $R$ is the universal gas constant and $T_{r}$ is the reference melt temperature.

\section{Crystallization kinetics}

The crystallization kinetics model adopted in this study was originally drawn by Ziabicki $[27,28]$ and later modified by Lamberti [60]. The quiescent conditions are defined as

$$
\mathrm{T}_{\mathrm{m}}=\mathrm{T}_{\mathrm{mq}}^{0}
$$


where $T_{m}$ is the melting temperature of the polymer and $T_{m q}^{0}$ is the flow-induced equilibrium melting temperature. Since the flow-induced crystallization is not included for the current study, the polymer melting temperature and flow-induced equilibrium melting temperature are equal.

The volume fraction of crystallized phase, $\chi_{c}$, and function $P(t)$ expressing the non-linear description of crystallinity evolution derived with respect to time as

$$
\chi_{c}(t)=\frac{X_{c}(t)}{X_{e q}}=1-\exp \left\{-[P(t)]^{n_{c}}\right\}
$$

where $X_{e q}$ is the equilibrium volume content of crystallinity (maximum in a crystal phase that melt can possess) and constant $n_{c}$ is of value 3 and thus nucleation is assumed as heterogeneous according to [28] with three-dimensional crystal evolution. After differentiation with respect to time, the time-evolution formula is

$$
\frac{\mathrm{dX}_{\mathrm{c}}(\mathrm{t})}{\mathrm{dt}}=-\mathrm{X}_{\mathrm{eq}} \exp \left\{-[\mathrm{P}(\mathrm{t})]^{\mathrm{n}_{\mathrm{c}}}\right\}\left\{-\mathrm{n}_{\mathrm{c}}[\mathrm{P}(\mathrm{t})]^{\mathrm{n}_{\mathrm{c}}-1}\right\} \frac{\mathrm{dP}(\mathrm{t})}{\mathrm{dt}}
$$

In the simplified form, the model kinetics proposed by Ziabicki [27, 28] and adopted in this work is as follows

$$
\begin{gathered}
K(t)=\frac{d}{d t} P(t) \\
K=K_{\text {th }}(1+\dot{T} Z)^{1 / n_{c}}
\end{gathered}
$$

Here, $K(t)$ is the crystallization kinetics constant representing crystallization rate, $K_{t h}$ term is responsible for the low cooling rate crystallization, $\kappa_{1}, \kappa_{2}$, and $E_{c}$ are material parameters determined from the isothermal test, $R$ is universal gas constant, $B_{\text {ath }}$ and $A_{\text {ath }}$ are material parameters included into the model by Lamberti considering cooling history and promoting the model to be capable to describe a crystallinity evolution at high cooling rates. Fitting parameters, $\kappa_{1}, \kappa_{2}, E_{c}, B_{a t h}$, and $A_{a t h}$, for the material used in this work were determined in [60]. 


$$
K_{\text {th }}=\kappa_{1} \frac{T\left(T_{m}-T\right)}{\left(T_{m}\right)^{2}} \exp \left[-\frac{E_{c}}{R T}\right] \exp \left[-\kappa_{2} \frac{\left(T_{m}\right)^{2}}{T\left(T_{m}-T\right)}\right]
$$

Effect of cooling rate on the crystallization kinetics constant is covered by a non-isothermal function, $Z$, taking the form of

$$
\mathrm{Z}=-\mathrm{B}_{\text {ath }}|\dot{\mathrm{T}}|^{\mathrm{A}_{\text {ath }}} \frac{\left(\mathrm{T}_{\mathrm{m}}\right)^{5}}{\mathrm{~T}\left(\mathrm{~T}_{\mathrm{m}}-\mathrm{T}\right)^{5}} \exp \left[\frac{\mathrm{E}_{\mathrm{c}}}{\mathrm{RT}}\right]
$$

where, the cooling rate is marked as $\dot{T}$, the derivative of the film temperature with respect to time, $t$. The formula for the transition from time to spatial coordinates is following

$$
\dot{\mathrm{T}}=\frac{\mathrm{dT}}{\mathrm{dt}}=\mathrm{u} \frac{\mathrm{dT}}{\mathrm{dx}}
$$

After its application on Eq. 27 with dimensionless transformation introduced in the previous section and some rearrangement, the final form of equation for the crystallinity evolution in dimensionless spatial coordinates demands

$$
\frac{\mathrm{dX}_{\mathrm{c}}(\overline{\mathrm{x}})}{\mathrm{d} \overline{\mathrm{x}}}=\mathrm{X}_{\mathrm{eq}} \exp \left\{-[\mathrm{P}(\overline{\mathrm{x}})]^{\mathrm{n}_{\mathrm{c}}}\right\} \mathrm{n}_{\mathrm{c}}[\mathrm{P}(\overline{\mathrm{x}})]^{\mathrm{n}_{\mathrm{c}}-1} \frac{\mathrm{dP}(\overline{\mathrm{x}})}{\mathrm{d} \overline{\mathrm{x}}} \frac{\mathrm{X}}{\overline{\mathrm{u}} \mathrm{u}_{0}}
$$

and semi-dimensionless form of the energy equation, Eq. 22, is then given as

$$
\frac{\mathrm{dT}}{\mathrm{d} \overline{\mathrm{x}}}=\frac{2 \mathrm{HTC}\left(\mathrm{T}_{\mathrm{a}}-\mathrm{T}\right) \overline{\mathrm{L} X}}{\mathrm{C}_{\mathrm{p}} \dot{\mathrm{m}}}+\frac{\Delta \mathrm{H}}{\mathrm{C}_{\mathrm{p}}} \frac{\mathrm{dX}}{\mathrm{d} \overline{\mathrm{x}}}
$$

\section{Effect of crystallinity on viscosity}

Besides the effect of temperature on the melt relaxation time, the effect of crystallinity on viscosity is included into the model through the function $\mu_{X c}$ that acts directly on the initial elastic modulus $G_{0}$; this approach was presented by Titomanlio in [68].

$$
\mathrm{G}=\mu_{\mathrm{X}_{\mathrm{c}}}\left(\mathrm{X}_{\mathrm{c}}\right) \mathrm{G}_{0}
$$


This S-shaped function remains unity as the amount of crystallinity in volume is low and at a certain point starts to deviate and sharply raise simulating the phase transition from the melt to the solid state:

$$
\mu_{X_{c}}\left(X_{c}\right)=1+f \exp \left(-\frac{h}{X_{c}^{m}}\right)
$$

It is worth to note that Eq. 12 is no more globally satisfied as in previous works where modulus $G$ was taken as a constant $[67,69]$ and must be treated as follows

$$
\int_{\bar{\tau}_{x x}(0)}^{\bar{\tau}_{x x}(X)} \mathrm{d} \bar{\tau}_{x x}-\int_{\bar{\tau}_{z z}(0)}^{\bar{\tau}_{z z}(X)} \mathrm{d} \bar{\tau}_{z z}-\int_{\bar{u}(0)}^{\bar{u}(X)} d \bar{u}=0
$$

\subsection{Boundary Conditions}

Proposed model equations can be mathematically solved only if appropriate boundary conditions for downstream, Eq. 38, and upstream region, Eq. 39, are defined.

$$
\begin{gathered}
\overline{\mathrm{u}}(\mathrm{X})=\mathrm{DR} \\
\overline{\mathrm{u}}(0)=1 \quad \overline{\mathrm{e}}(0)=1 \quad \overline{\mathrm{L}}(0)=1 \\
-\frac{\mathrm{N}_{2}(0)}{\mathrm{N}_{1}(0)}=0.2 \\
\mathrm{X}_{\mathrm{c}}(0)=0 \quad \mathrm{~T}(0)=\mathrm{T}_{\mathrm{DIE}}
\end{gathered}
$$

Regarding the downstream region, only the desired value of draw ratio must be prescribed that is satisfied by a priori unknown magnitude of the drawing force which is an object of search. In the upstream area (i.e. extrusion die exit region), the count of required values is broader and includes the definition of axial velocity, die dimensions, that is gap size and width, which are equal to unity due its dimensionless expression, and melt temperature, and crystallinity that is assumed to be zero. Due to the employed viscoelastic constitutive equations, the stress state at 
the die has to be imposed, therefore the diagonal components of the extra stress tensor $\bar{\tau}_{x x}, \bar{\tau}_{y y}$ , and $\bar{\tau}_{z z}$ are calculated through Eq. 15 utilizing $c_{x x}, c_{y y}$, and $c_{z z}$ components of the recoverable strain tensor satisfying the following set of equations

$$
\begin{gathered}
\frac{E}{D e}\left[\left(c_{x x}-c_{z z}\right)(1-\beta)+\beta\left(c_{z z}^{-1}-c_{x x}^{-1}\right)\right]-1=0 \\
c_{x x} c_{y y} c_{z z}=1 \\
-\frac{N_{2}}{N_{1}}=\frac{E\left[c_{z z}-c_{y y}+\beta\left(c_{y y}+c_{y y}^{-1}-c_{z z}-c_{z z}^{-1}\right)\right]}{D e}
\end{gathered}
$$

where Eq. 40 arises from the momentum conservation equation (Eq. 12), Eq. 41 from the melt incompressibility assumption. Eq. 43 characterizes the polymer melt stress state at the die exit region as the ratio of the secondary to primary normal stress difference, $-N_{2} / N_{1}$, and is calculated from the fully-developed slit flow at the extrusion die exit as follows

$$
-\frac{\mathrm{N}_{2}}{\mathrm{~N}_{1}}=-\frac{\bar{\tau}_{\mathrm{zz}}(0)-\bar{\tau}_{\mathrm{yy}}(0)}{\bar{\tau}_{\mathrm{xx}}(0)-\bar{\tau}_{\mathrm{zz}}(0)}
$$

\subsection{Numerical Scheme}

To solve the full set of first-order ordinary differential equations, the numerical scheme based on the $4^{\text {th }}$ order Runge-Kutta method implementing adaptive step-size control was adopted. The process of calculation is commenced by guessing a value of drawing force followed by iterative determination of the stress boundary condition via Eqs. 40-43. Then the main set of eight differential equation is solved in the following order: crystallization kinetics (Eq. 33), energy of equation (Eq. 34), film half-width (Eq. 13), axial velocity (Eq. 21), film half-thickness (Eq. 14) and components of the recoverable elastic strain tensor (Eqs. 16-18). Depending on wheatear the desired draw ratio is achieved, the initially estimated drawing force 
was iteratively updated (increased/decreased) for every following calculation until convergence (see Figure 2) using the bisection method. Oscillations in temperature profile development, that were occasionally present in calculations causing the instability of computation, were fixed by applied stabilizing method of weighting the result of Eq. 34 for actual and previous position $x$. Due to a geometrical symmetry of the film, only $1 / 4^{\text {th }}$ of the film cross-section was used in the calculation as showed in [70]. This basic computational scheme for the determination of unknown process variables was looped according to demands of currently conducted parametric studies and eventually complemented by the module for a grid linear interpolation to create parametric maps. The entire solver was developed in the $\mathrm{C}++$ programming language and coupled with GNUPLOT plotting software for automatic graph generation. Typical computational time for one calculation of prescribed $D R$ was about 1 minute on the PC with the following hardware specifications: CPU: Intel Core i7-7700 at $3.60 \mathrm{GHz}, \mathrm{RAM}$ : $32 \mathrm{~GB}$ DDR4, GPU: AMD Radeon Pro WX 4100 with 4 GB of video memory, SSD: HP Z TurboDrive G2 512 GB. 


\section{RESULTS AND DISCUSSION}

\subsection{Model validation}

Proposed non-isothermal film casting model has been tested for well characterized linear isotactic PP (for the basic characteristics see Table 1) and given processing conditions $[9,10]$. All model parameters for given material and processing conditions are summarized in Table 2 and Table 3, respectively. In this work, single-mode modified Leonov model utilizing the lowest relaxation time, $\lambda_{0}=0.01 \mathrm{~s}$, which is typical for polyolefins $[71,72]$, was used. It was shown by Thete et al. [72] that utilization of lowest relaxation time in the cast film modeling can provide reasonable stress predictions in both, axial and transverse directions. Knowing Newtonian viscosity, $\eta_{0}=\lambda_{0} \cdot \mathrm{G}_{0}$, and relaxation time at $\mathrm{T}_{\mathrm{r}}=220^{\circ} \mathrm{C}$, temperature independent modulus $G_{0}$ was calculated to be $740,199 \mathrm{~Pa}$. The crystallization kinetics parameters in the function given by Eq. 33 were set for given material according to [60], see Table 4. It was shown that the modulus increases significantly with the film crystallinity $[7,14,73,74]$, which can be taken into account during cast film modeling via Eq. 35. In this work, the adjustable parameters of Eq. 36 were chosen according to Table 5 in order to predict significant modulus increase even at very low crystallinity levels, which seems to be reasonable [7, 14]. Due to the fact that tested iPP melt is linear, i.e., it shows extensional strain thinning, modified Leonov parameters $\xi$ and $v$, appearing in Eq. 7 for dissipation function, were adjusted to be equal to 0 and 0.5 , respectively, whereas the parameter $\beta$ in Eq. 3 was adjusted to be 0.5 (just between 0 and 1 meaning that the first as well as second invariant of recoverable Finger tensor contributes equally to the elastic potential). Deborah number at the die exit is equal to $6 \cdot 10^{-4}$ for given material and processing conditions (i.e. much lower than 0.3 ), which means that there is no role of die exit stress state on the post die calculations as shown in our previous work [69]. Thus, the second to first normal stress ratio at the die exit was kept the same in all calculations, $-N_{2} / N_{1}=0.2$ according to [75]. The only free parameter in the presented model 
is the heat transfer coefficient, $H T C$, appearing in the energy equation, Eq. 34. This parameter is not a priory known and thus its value was adjusted $16 \mathrm{~J} \cdot \mathrm{s}^{-1} \cdot \mathrm{K}^{-1} \cdot \mathrm{m}^{-2}$ in order to capture experimentally determined temperature profile between die and chill roll. Comparison between proposed model predictions and experimental data for linear iPP and given processing conditions $\left(\mathrm{T}_{\mathrm{DIE}}=200^{\circ} \mathrm{C}, \mathrm{De}=6 \cdot 10^{-4}, \mathrm{DR}=34.7, \mathrm{X}=0.4 \mathrm{~m}, \dot{\mathrm{m}}=1.26 \cdot 10^{-4} \mathrm{~kg} \cdot \mathrm{s}^{-1}\right)$ is provided in Figure 3. As can be seen, model predictions utilizing the lowest relaxation time for film halfwidth, axial velocity, temperature and crystallinity (especially at high draw distances) are in good agreement with the corresponding experimental data. This can be attributed to rapid cooling, which increases relaxation time and modulus three orders of magnitude each so that the longest relaxation (from reptation) is less effective in this case. The fact, that the nonisothermal model is capable to describe experimental reality for linear iPP at given processing conditions justify to use the model in the detailed parametric study.

\subsection{Parametric study}

3.2.1 The role of heat transfer coefficient, draw and aspect ratio on the onset of crystalline phase in the produced film

The key step in production of PP porous membranes is production of a precursor film with a row-nucleated lamellar structure [45], i.e. with shish-kebab crystalline phase created due to extensional flow in the post die area, which consists of an extended chain crystal (a "shish") and folded chain crystals ("kebabs") [76]. The processing window is thus the rather narrow and detailed role of processing conditions on the development crystalline phase in the resulting film is still rather unclear. In this work, the processing window is defined as the conditions (given by aspect and draw ratios, $T_{D I E}$, and heat transfer coefficient), during which produced film contains non-zero crystalline phase. An example is provided in Figure 4 for one fixed heat transfer coefficient value $2.5 \mathrm{~J} \cdot \mathrm{s}^{-1} \cdot \mathrm{K}^{-1} \cdot \mathrm{m}^{-2}$. Here, the area above the symbols (calculated by the numerical model) represents the processing conditions leading to non-zero crystallinity whereas 
space below them characterizes the region with no crystalline phase in the produced film. In this case, experimental process conditions used in the validation study are considered to be the reference. The predicted trend visualized in Figure 4 (i.e. that low draw ratios, which correspond to longer processing times, give rise to crystalline phase but high draw ratios do not because processing time is too short for crystallization) corresponds well with the experimental data provided in [77]. Note that numerical model predictions given by the symbols used in Figure 4 to determine process conditions for crystalline and no-crystalline phase development are entitled here as the "border symbols".

In order to understand the role of process conditions on the onset of crystalline phase development in produced film, the following variables were systematically varied in particular ranges: aspect ratio $(0.25-4)$, draw ratio (3-140), heat transfer coefficient $\left(1.5-28 \mathrm{~J} \cdot \mathrm{s}^{-1} \cdot \mathrm{K}^{-1} \cdot \mathrm{m}^{-2}\right)$ and die exit melt temperature $\left(200,225\right.$, and $\left.250^{\circ} \mathrm{C}\right)$. The chosen ranges correspond to typical values used in the real production of PP porous membranes [45, 47, 78, 79].

Numerical model predictions for "border symbols" at given a range of processing conditions are visualized in Figures 5-7. As can be seen, the processing window for production of film containing crystalline phase is enlarged if $T_{D I E}$ decreases or $H T C$ or $A$ increases. This promotes to reach crystallization temperature in the film between the die and the chill roll. Interestingly, the relationship between $A$ and $D R$ defining "border symbols" for different $T_{D I E}$ and $H T C$ is linear. This suggests that all numerically predicted data visualized in Figure 5-7 as the symbols can be easily approximated by a simple analytical equation.

\subsubsection{Analytical approximation for critical crystallization border}

The following simple analytical equation was chosen to approximate numerical solutions for the determination of critical border contour in $A$ vs. $D R$ processing diagrams visualized in Figures 5-7 for different $T_{D I E}$ and $H T C$. 


$$
A=\exp \left[q\left(H T C, T_{D I E}\right)\right] D^{k\left(H T C, T_{D I E}\right)}
$$

where $q\left(H T C, T_{D I E}\right)$ and $k\left(H T C, T_{D I E}\right)$ are given as

$$
\begin{gathered}
\mathrm{k}\left(\mathrm{HTC}, \mathrm{T}_{\mathrm{DIE}}\right)=\left(\gamma_{\mathrm{k}} \mathrm{T}_{\mathrm{DIE}}+\delta_{\mathrm{k}}\right) \mathrm{HTC}^{\left(\alpha_{\mathrm{k}} \mathrm{T}_{\mathrm{DIE}}+\beta_{\mathrm{k}}\right)} \\
\mathrm{q}\left(\mathrm{HTC}, \mathrm{T}_{\mathrm{DIE}}\right)=\left(\alpha_{\mathrm{q}} \mathrm{T}_{\mathrm{DIE}}+\beta_{\mathrm{q}}\right) \ln (\mathrm{HTC})+\left(\gamma_{\mathrm{q}} \mathrm{T}_{\mathrm{DIE}}+\delta_{\mathrm{q}}\right)
\end{gathered}
$$

These equations utilize 3 independent variables $\left(D R, H T C\right.$, and $\left.T_{D I E}\right)$ and 8 adjustable parameters $\left(\alpha_{k}, \beta_{k}, \gamma_{k}, \delta_{k}, \alpha_{q}, \beta_{q}, \gamma_{q}, \delta_{q}\right)$. Analytical equation, Eq. 44, was used to simultaneously fit all numerically determined "border symbols" depicted in Figures 5-7 through last square minimization method and obtained optimum parameters are summarized in Table 6. As it can be seen in Figures 5-7, an agreement between fitting lines and numerically obtained "border symbols" is very good. Thus, Eq. 44 together with its parameters can be considered as a reliable approximation of true numerical solutions of "border symbols" for linear iPP at a given range of processing conditions.

3.2.3 Determination of processing conditions, at which the Neck-in phenomenon starts to be influenced by heat transfer coefficients and crystallization

It was shown that during production of transparent flat films via cast film technology (i.e. at very high temperatures/draw ratios and very small die-roll distances, where no crystalline phase is developed) the neck in phenomenon (unwanted shrinkage of the film in the width direction) can be reliably predicted via isothermal simulations where the heat transfers and crystallization are neglected $[67,69]$. It is obvious that there are processing conditions, for which isothermal simulations are too simplistic and therefore the neck-in phenomenon cannot be predicted realistically. Thus, the key question is "what are the processing conditions for linear iPP, at which heat transfer coefficients and crystallization starts to influence the neck-in phenomenon"? In order to answer this question, $D R, A$, and $H T C$ were systematically varied in the proposed numerical model for the reference processing conditions at the lowest 
investigated melt temperature at the die exit, for which the need to utilize non-isothermal calculation is the most probable. For all investigated processing conditions, both, isothermal as well as non-isothermal calculations have been performed. For each simulated case, neck-in value at the chill roll was evaluated. If differences between neck-in values obtained from isothermal and non-isothermal calculations were lower than $5 \%$, it was considered that neck-in predictions from isothermal calculations were reliable and non-isothermal effects can be viewed as negligible. For the processing conditions, in which differences in neck-in were higher than $5 \%$, it was considered that non-isothermal effects have to be included in the numerical simulations. Results of the performed parametric study are visualized in Figures 8-10. Here, the "isothermality boundary symbols" represent processing conditions, at which neck-in differences between isothermal and non-isothermal calculations were $5 \%$ for given $H T C$ value. The area below these symbols represents processing conditions for which isothermal calculations provide a good estimate for the neck-in phenomenon whereas above these symbols, non-isothermal effects have to be taken into account to predict neck-in reliably. For the wide range of $H T C$, it was possible to approximate numerical solutions for "isothermality boundary symbols" via the same set of simple analytical equations as for the critical crystallization border, Eqs. 44-46, but utilizing different set of parameters $\left(\alpha_{k}, \beta_{k}, \gamma_{k}, \delta_{k}, \alpha_{q}, \beta_{q}, \gamma_{q}, \delta_{q}\right)$, which are summarized in Table 7. As can be seen in Figures 8-10, Eq. 44 can approximate numerical solutions very well for the following range of variables:

$\mathrm{DR} \in\langle 3-140\rangle, \mathrm{A} \in\langle 0.25-4\rangle, \mathrm{T} \in\langle 200-250\rangle{ }^{\circ} \mathrm{C}$ and $\mathrm{HTC} \in(4-30\rangle \mathrm{J} \cdot \mathrm{s}^{-1} \cdot \mathrm{K}^{-1} \cdot \mathrm{m}^{-2}$.

\subsubsection{Effect of $A, D R, H T C, T_{D I E}$ on cast film process}

In this part, $A, D R, H T C$, and $T_{D I E}$ were systematically varied in the numerical model considering the reference processing conditions $\left(\mathrm{HTC}=16 \mathrm{~J} \cdot \mathrm{s}^{-1} \cdot \mathrm{K}^{-1} \cdot \mathrm{m}^{-2}, \mathrm{~T}_{\mathrm{DIE}}=200^{\circ} \mathrm{C}, \mathrm{DR}=37.4\right.$, 
$\mathrm{X}=0.4 \mathrm{~m}$ ) in order to understand their effect on the dimensionless film half-width and axial velocity, temperature, and crystallinity; all as the function of dimensionless drawing distance.

In the first step, the aspect ratio, $A$, was varied from 0.01 up to 10 (via changing drawing distance) keeping another reference processing conditions fixed. Results are provided in Figure 9. From here, it is visible that if $A$ increases, the neck-in increases, axial velocity profile is changing from a convex to concave shape, film temperature decreases, and crystallinity increases.

In the second step, the draw ratio, $D R$, was changing from 3 to 140 (via step increase in take-up speed). Obtained numerical results are provided in Figure 12. Obviously, an increase in $D R$ leads to higher neck-in, axial film velocity, final film temperature and lower crystallinity.

In the third step, the heat transfer coefficient, $H T C$, was varied from 0 to $100 \mathrm{~J} \cdot \mathrm{s}^{-1} \cdot \mathrm{K}^{-1} \cdot \mathrm{m}^{-2}$. As it can be seen from Figure 13, an increase in $H T C$ causes a reduction in neck-in, the change of axial velocity profile from a convex to concave shape as well as decrease in film temperature. There is an interesting not fully intuitive relationship between $H T C$ and film crystallinity. In more detail, there is a range of HTCs $0-3 \mathrm{~J} \cdot \mathrm{s}^{-1} \cdot \mathrm{K}^{-1} \cdot \mathrm{m}^{-2}$, for which the final film does not contain any crystalline phase. If the $H T C$ increases above some critical value (in this case above $3 \mathrm{~J} \cdot \mathrm{s}^{-1} \cdot \mathrm{K}^{-1} \cdot \mathrm{m}^{-2}$ ), film crystallinity increases, reaching the maximum and then decreasing. This suggests that there exists optimum $H T C$ for given material and processing conditions, at which the amount of crystalline phase is maximal.

In the final step, melt temperature at the die exit, $T_{D I E}$, was varied from 150 to $300^{\circ} \mathrm{C}$. Obtained model predictions are visualized in Figure 14. Clearly, a decrease in $T_{D I E}$ increases the neck-in and crystallinity whereas the film temperature and axial velocity are reduced. 


\subsubsection{Note on pros and cons of utilized membrane approach for cast film modeling}

Utilized a pseudo 2D or 1.5D membrane approach possessing the benefits of a reasonable simplicity and numerical stability. Nevertheless, the compromise made on the assumptions of a flow kinematics having an ability to predict the film width retraction implies certain drawbacks. The distribution of flow types, that is a planar and uniaxial extensional flow at the film center and peripheral regions, respectively, as observed in [80], is not fully covered by this approach due to assumed linear variation of lateral velocities [61] in a given axial position. As a result, the model is not capable to predict edge-bead defect (edge portions of the film are thicker than its central part). Assumption that the heat transfer coefficient (HTC) is constant during the process allows both, simple determination of HTC from the known temperature profile as well as straightforward parametric study to elucidate basic role of HTC. This can be considered as an advantage of the chosen approach. Of course, in reality, the heat transfer is complex, driven by a forced and natural convection as well as a heat radiation emitting from the film surface where change in the processing conditions (stretching distance, film speed, film temperature), parameters of the surrounding gas (thermal conductivity, density, viscosity, specific heat capacity, volumetric expansion coefficient) and used polymer (emissivity) has effect on the HTC. Thus, with respect to the essential 1.5D film casting model kinematics utilized in this study, it seems that current state of a development has approached to its limits and a great space and opportunity for partial improvement lays in extending the model considering for macromolecule orientation and flow-induced crystallization, more realistic description of heat transfer via variable heat transfer coefficient or incorporation of multi-mode approach for material description. 


\section{CONCLUSIONS}

In this work, stable numerical scheme has been developed for $1.5 \mathrm{D}$ film casting model of Silagy et al. [57] utilizing viscoelastic modified Leonov model as the constitutive equation $[58,59]$ and energy equation coupled with crystallization kinetics of semicrystalline polymers taking into account actual temperature as well as temperature gradient $[27,28,60]$. The model has been successfully validated on the experimental data for linear isotactic polypropylene taken from the open literature [10].

Aspect ratio, A, (0.25-4), draw ratio, DR, (3-140), heat transfer coefficient, HTC, $\left(1.5-28 \mathrm{~J} \cdot \mathrm{s}^{-1} \cdot \mathrm{K}^{-1} \cdot \mathrm{m}^{-2}\right)$ and die exit melt temperature, $T_{D I E},\left(200,225\right.$, and $\left.250^{\circ} \mathrm{C}\right)$ were systematically varied in the utilized model in order to understand the role of process conditions on the onset of crystalline phase development in production of iPP flat porous membranes via cast film process. It was found that numerically predicted critical crystallization border in $A$ vs. $D R$ dependence for given $H T C$ and $T_{D I E}$ can be successfully approximated by a simple analytical equation.

Utilizing isothermal as well as non-isothermal numerical calculations, it was possible to determine processing conditions (in terms of $D R, A, T_{D I E}$, and $H T C$ ) for linear iPP, for which isothermal simulations are too simplistic and therefore the neck-in phenomena cannot be predicted realistically. It was possible to find out suitable analytical approximation for the “isothermality boundary" in $A$ vs. $D R$ dependence for different $H T C s$, which is applicable within the following range of processing variables: $\mathrm{DR} \in\langle 3-140\rangle, \mathrm{A} \in\langle 0.25-4\rangle$, $\mathrm{T} \in\langle 200-250\rangle{ }^{\circ} \mathrm{C}$ and $\mathrm{HTC} \in(4-30\rangle \mathrm{J} \cdot \mathrm{s}^{-1} \cdot \mathrm{K}^{-1} \cdot \mathrm{m}^{-2}$.

Finally, the effect of $A, D R, H T C$, and $T_{D I E}$ on the dimensionless film half-width and axial velocity, temperature and crystallinity (all as the function of dimensionless drawing distance) was systematically investigated via non-isothermal simulations for linear iPP. It was found that neck-in can be reduced if $A$ or $D R$ decreases or if $H T C$ or $T_{D I E}$ increases. It has also been shown 
that produced film crystallinity increases if $A$ increases or if $D R$ or $T_{D I E}$ decreases. The most interestingly, it has been revealed that if the HTC increases above some critical value, film crystallinity increases, reaching the maximum and then decreasing. This suggests that there exists optimum $H T C$ for given material and processing conditions, at which the amount of crystalline phase is maximal. It is believed that the utilized numerical model together with suggested stable numerical scheme as well as obtained research results can help to understand a processing window for the production of flat porous membranes from linear iPP considerably.

\section{Acknowledgments}

The authors wish to acknowledge the financial support from the Grant Agency of the Czech Republic (Grant registration No. 16-05886S). 


\section{LIST OF SYMBOLS}

Latin Symbols Meaning Unit

A Aspect ratio

$\mathrm{A}_{\text {ath }} \quad$ Fitting parameter in crystallization kinetics $\quad 1$

$\mathrm{B}_{\mathrm{ath}} \quad$ Fitting parameter in crystallization kinetics $\quad \mathrm{S}$

b Dissipation term $\quad \mathrm{s}^{-1}$

$\overline{\mathrm{b}} \quad$ Dimensionless dissipation term 1

$\stackrel{\mathrm{c}}{=} \quad$ Recoverable Finger tensor $\quad 1$

$\stackrel{\mathrm{c}}{=}^{-1} \quad$ Inverse recoverable Finger tensor 1

0
$\mathrm{c}$ $\mathrm{s}^{-1}$

$\stackrel{\mathrm{c}}{=} \quad$ recoverable Finger strain tensor

$\mathrm{C}_{\mathrm{p}} \quad$ Specific heat capacity of polymer $\mathrm{J} \cdot \mathrm{kg}^{-1} \cdot \mathrm{K}^{-1}$

Normal component of the recoverable Finger tensor

$\mathrm{c}_{\mathrm{xx}}$

in axial $\mathrm{x}$-direction

Normal component of the recoverable Finger tensor

$c_{\text {yy }}$

in transverse $y$-direction

Normal component of the recoverable Finger tensor

$\mathrm{c}_{\mathrm{zz}}$

in thickness z-direction

$\underline{D} \quad$ Deformation rate tensor

$\mathrm{s}^{-1}$

De Deborah number

DR

Draw ratio

$\stackrel{\mathrm{e}}{=} \mathrm{p}$

Irreversible rate of strain tensor

$\mathrm{S}^{-1}$

E

Dimensionless take-up force

1

$\mathrm{E}_{\mathrm{a}}$

Flow activation energy

$\mathrm{J} \cdot \mathrm{mol}^{-1}$

$\mathrm{E}_{\mathrm{c}} \quad$ Fitting parameter in crystallization kinetics

K 
Die half-gap (half-thickness of the film at the die

$\mathrm{e}_{0}$

$\overline{\mathrm{e}}$

F

$\mathrm{f}, \mathrm{h}, \mathrm{m}$

$f(x)$

G

$\mathrm{G}_{0}$

HTC

$\mathrm{g}(\mathrm{x})$

i

$\mathrm{I}_{1, \mathrm{c}}$

$\mathrm{I}_{2, \mathrm{c}}$

$\mathrm{K}(\mathrm{t})$

$\mathrm{K}_{\mathrm{th}}$

$\mathrm{k}$

$\mathrm{L}$

$\mathrm{L}_{0}$

$\overline{\mathrm{L}}$

MFR , $\dot{\mathrm{m}}$

$M_{n}$ exit)

m

1 location

Take-up force (drawing force)

$\mathrm{N}$

Parameters in function describing the effect of crystallinity on elastic modulus

$\mathrm{s}^{-1}$

$\mathrm{Pa}$

$\mathrm{Pa}$

$\mathrm{J} \cdot \mathrm{s}^{-1} \cdot \mathrm{K}^{-1} \cdot \mathrm{m}^{-2}$

Heat transfer coefficient

Rate of deformation in thickness z-direction

$\mathrm{s}^{-1}$

Index $i$, noting the spatial direction

1

First invariant of recoverable Finger tensor

1

Second invariant of recoverable Finger tensor

1

$\mathrm{s}^{-1}$

$\mathrm{s}^{-1}$

Isothermal function of crystallization kinetics

1

Slope function in the suggested analytical equation

$\mathrm{m}$

Half-width of the die (half-width of the film at the die exit)

$\mathrm{m}$

Dimensionless half-width of the film at any $x$ location

1

$\mathrm{kg} \cdot \mathrm{h}^{-1}$

Mass flow rate

g. $\mathrm{mol}^{-1}$ 


\begin{tabular}{|c|c|c|}
\hline $\mathrm{M}_{\mathrm{w}}$ & Mass average molar mass & $\mathrm{g} \cdot \mathrm{mol}^{-1}$ \\
\hline $\mathrm{N}_{1}$ & First normal stress difference & $\mathrm{Pa}$ \\
\hline $\mathrm{N}_{2}$ & Second normal stress difference & $\mathrm{Pa}$ \\
\hline $\mathrm{n}$ & Non-linear Leonov model parameter & 1 \\
\hline $\mathrm{n}_{\mathrm{c}}$ & Type of crystallization growth & 1 \\
\hline $\mathrm{P}(\mathrm{t})$ & Function of non-linear crystallinity evolution & 1 \\
\hline $\mathrm{q}$ & $\begin{array}{l}\text { Intercept function in the suggested analytical } \\
\text { equation }\end{array}$ & 1 \\
\hline $\mathrm{R}$ & Gas constant & $\mathrm{J} \cdot \mathrm{K}^{-1} \cdot \mathrm{mol}^{-1}$ \\
\hline$\dot{\mathrm{T}}$ & Rate of cooling & ${ }^{\circ} \mathrm{C} \cdot \mathrm{s}^{-1}$ \\
\hline $\mathrm{T}_{\mathrm{DIE}}$ & Melt temperature at the die & ${ }^{\circ} \mathrm{C}$ \\
\hline $\mathrm{T}_{\mathrm{m}}$ & Melting temperature of polymer & ${ }^{\circ} \mathrm{C}$ \\
\hline $\mathrm{T}_{\mathrm{mq}}^{0}$ & Flow-induced equilibrium melting temperature & ${ }^{\circ} \mathrm{C}$ \\
\hline $\mathrm{T}$ & Melt temperature & ${ }^{\circ} \mathrm{C}$ \\
\hline $\mathrm{T}_{\mathrm{r}}$ & Reference temperature in the Arrhenius law & ${ }^{\circ} \mathrm{C}$ \\
\hline $\mathrm{u}$ & $\begin{array}{l}\text { Axial velocity component of the film at any } \\
x \text { location }\end{array}$ & $\mathrm{m} \cdot \mathrm{s}^{-1}$ \\
\hline $\mathrm{u}(\mathrm{X})$ & Chill roll speed & $\mathrm{m} \cdot \mathrm{s}^{-1}$ \\
\hline $\mathrm{u}_{0}$ & Axial velocity component at the die exit & $\mathrm{m} \cdot \mathrm{s}^{-1}$ \\
\hline$\overline{\mathrm{u}}$ & $\begin{array}{l}\text { Dimensionless axial velocity component of the film } \\
\text { at any } x \text { location }\end{array}$ & 1 \\
\hline $\mathrm{v}$ & $\begin{array}{l}\text { Transverse velocity component of the film at any } \\
x \text { location }\end{array}$ & $\mathrm{m} \cdot \mathrm{s}^{-1}$ \\
\hline $\mathrm{W}$ & Elastic potential & $\mathrm{Pa}$ \\
\hline$N$ & $\begin{array}{l}\text { Thickness velocity component of the film at any } \\
x \text { location }\end{array}$ & $\mathrm{m} \cdot \mathrm{s}^{-1}$ \\
\hline
\end{tabular}




\begin{tabular}{|c|c|}
\hline $\mathrm{X}$ & Take-up length (stretching distance, air gap) \\
\hline $\mathrm{x}$ & Position in axial $\mathrm{x}$-direction \\
\hline$\overline{\mathrm{x}}$ & Dimensionless position in axial $\mathrm{x}$-direction \\
\hline $\mathrm{x}, \mathrm{y}, \mathrm{z}$ & $\begin{array}{l}\text { Spatial coordinates in axial, transverse and thickness } \\
\text { direction, respectively }\end{array}$ \\
\hline$X_{c}$ & Crystallinity content in the polymer volume \\
\hline$X_{\text {eq }}$ & $\begin{array}{l}\text { Equilibrium level of crystallinity in the polymer } \\
\text { volume }\end{array}$ \\
\hline $\mathrm{Z}$ & Non-isothermal function of crystallization kinetics \\
\hline$Z_{x}, Z_{y}, Z_{z}$ & Substitution variables \\
\hline$\frac{\mathrm{dc}_{\mathrm{xx}}}{\mathrm{d} \overline{\mathrm{x}}}, \frac{\mathrm{dc}_{\mathrm{yy}}}{\mathrm{d} \overline{\mathrm{x}}}, \frac{\mathrm{dc}_{\mathrm{zz}}}{\mathrm{d} \overline{\mathrm{x}}}$ & $\begin{array}{l}\text { Derivative of Finger tensor components with respect } \\
\text { to dimensionless } \bar{x} \text { position }\end{array}$ \\
\hline$\frac{\mathrm{d} \overline{\mathrm{u}}}{\mathrm{d} \overline{\mathrm{x}}}, \frac{\mathrm{d} \overline{\mathrm{L}}}{\mathrm{d} \overline{\mathrm{x}}}, \frac{\mathrm{d} \overline{\mathrm{e}}}{\mathrm{d} \overline{\mathrm{x}}}$ & $\begin{array}{l}\text { Derivative of dimensionless axial velocity, width } \\
\text { and thickness with respect to dimensionless } \bar{x} \\
\text { position }\end{array}$ \\
\hline$\frac{d X_{c}}{d \bar{x}}$ & $\begin{array}{l}\text { Derivative of crystallinity with respect to } \\
\text { dimensionless } \bar{x} \text { position }\end{array}$ \\
\hline $\mathrm{dT}$ & Derivative of temperature with respect to \\
\hline$\overline{\mathrm{d} \overline{\mathrm{x}}}$ & dimensionless $\bar{x}$ position \\
\hline
\end{tabular}

Greek Symbols Meaning Unit

$\alpha_{\mathrm{k}}, \beta_{\mathrm{k}}, \gamma_{\mathrm{k}}, \delta_{\mathrm{k}}, \quad$ Fitting parameters in the suggested analytical $\alpha_{q}, \beta_{q}, \gamma_{q}, \delta_{q} \quad$ equation Arrhenius law parameter

$\beta \quad$ Non-linear Leonov model parameter 1

$\Delta \mathrm{H} \quad$ Crystallization latent heat $\quad \mathrm{kJ} \cdot \mathrm{kg}^{-1}$

$\underline{\underline{\delta}} \quad$ Unit tensor (Kronecker delta) 1 


\begin{tabular}{|c|c|c|}
\hline$\eta_{0}$ & Newtonian viscosity & $\mathrm{Pa} \cdot \mathrm{s}$ \\
\hline$\kappa_{1}$ & Fitting parameter in crystallization kinetics & $\mathrm{s}^{-1}$ \\
\hline$\kappa_{2}$ & Fitting parameter in crystallization kinetics & 1 \\
\hline$\lambda$ & Melt relaxation time & $\mathrm{s}$ \\
\hline$\lambda_{0}$ & Melt relaxation time at the die exit & $\mathrm{s}$ \\
\hline$\mu_{\mathrm{x}_{\mathrm{c}}}$ & Effect of crystallinity on elastic modulus function & 1 \\
\hline$v$ & Non-linear Leonov model parameter & 1 \\
\hline$\xi$ & Non-linear Leonov model parameter & 1 \\
\hline$\rho_{\mathrm{P}}$ & Polymer density & $\mathrm{kg} \cdot \mathrm{m}^{-3}$ \\
\hline$\stackrel{\tau}{=}$ & Extra stress tensor & $\mathrm{Pa}$ \\
\hline$\tau_{\mathrm{xx}}$ & Normal stress in axial $\mathrm{x}$-direction & $\mathrm{Pa}$ \\
\hline$\tau_{\mathrm{yy}}$ & Normal stress in transverse y-direction & $\mathrm{Pa}$ \\
\hline$\tau_{\mathrm{zz}}$ & Normal stress in thickness z-direction & $\mathrm{Pa}$ \\
\hline $\bar{\tau}_{\mathrm{xx}}$ & Dimensionless normal stress in axial x-direction & 1 \\
\hline $\bar{\tau}_{\mathrm{yy}}$ & $\begin{array}{l}\text { Dimensionless normal stress in transverse } \\
\text { y-direction }\end{array}$ & 1 \\
\hline $\bar{\tau}_{\mathrm{zz}}$ & Dimensionless normal stress in thickness z-direction & 1 \\
\hline$\chi_{\mathrm{c}}$ & Volume fraction of crystallized phase & 1 \\
\hline
\end{tabular}




\section{REFERENCES}

1. D. Cotto, P. Duffo, and J. M. Haudin, Int. Polym. Process. 4, 103 (1989).

2. P. Duffo, B. Monasse, and J. M. Haudin, J. Polym. Eng. 10, 151 (1991).

3. P. Barq, J. M. Haudin, and J. F. Agassant, Int. Polym. Process. 7, 334 (1992).

4. S. Bourrigaud, G. Marin, V. Dabas, C. Dupuy, and D. Silagy, Polym. Eng. Sci. 46, 372 (2006).

5. D. Acierno, L. Di Maio, and C. C. Ammirati, Polym. Eng. Sci. 40, 108 (2000).

6. S. Coppola, L. Balzano, E. Gioffredi, P. L. Maffettone, and N. Grizzuti, Polymer 45, 3249 (2004).

7. G. Lamberti, G. Titomanlio, and V. Brucato, Chem. Eng. Sci. 56, 5749 (2001).

8. G. Lamberti, G. Titomanlio, and V. Brucato, Chem. Eng. Sci. 57, 1993 (2002).

9. G. Lamberti, V. Brucato, and G. Titomanlio, J. Appl. Polym. Sci. 84, 1981 (2002).

10. G. Lamberti, and G. Titomanlio, Macromol. Symp. 185, 167 (2002).

11. G. Lamberti, and V. Brucato, J. Polym. Sci. Part B Polym. Phys. 41, 998 (2003).

12. G. Lamberti, V. La Carrubba, S. Piccarolo, and V. Brucato, Polym. Bull. 50, 413 (2003).

13. G. Titomanlio, and G. Lamberti, Rheol. Acta 43, 146 (2004).

14. G. Lamberti, and G. Titomanlio, Chem. Eng. Process. Process Intensif. 44, 1117 (2005).

15. G. Lamberti, and F. De Santis, Heat Mass Transf. 43, 1143 (2006).

16. G. Lamberti, and G. Titomanlio, Ind. Eng. Chem. Res. 45, 719 (2006).

17. G. Lamberti, Polym. Eng. Sci. 51, 851 (2011).

18. A. N. Kolmogoroff, Isvest. Akad. Nauk SSSR Ser. Math. 1, 335 (1937).

19. M. Avrami, J. Chem. Phys. 8, 212 (1940).

20. U. R. Evans, Trans. Faraday Soc. 41, 365 (1945).

21. A. N. Kolmogorov, Izv. Akad. Nauk SSSR, Ser. Mat. 3, 355 (1937).

22. M. Avrami, J. Chem. Phys. 7, 1103 (1939).

23. M. Avrami, J. Chem. Phys. 9, 177 (1941).

24. K. Nakamura, T. Watanabe, K. Katayama, and T. Amano, J. Appl. Polym. Sci. 16, 1077 (1972).

25. K. Nakamura, K. Katayama, and T. Amano, J. Appl. Polym. Sci. 17, 1031 (1973).

26. T. Ozawa, Polymer 12, 150 (1971).

27. A. Ziabicki, Colloid Polym. Sci. 274, 209 (1996).

28. A. Ziabicki, Colloid Polym. Sci. 274, 705 (1996).

29. V. Brucato, G. Crippa, S. Piccarolo, and G. Titomanlio, Polym. Eng. Sci. 31, 1411 (1991).

30. S. Piccarolo, M. Saiu, V. Brucato, and G. Titomanlio, J. Appl. Polym. Sci. 46, 625 (1992). 
31. V. Mathot, M. Pyda, T. Pijpers, G. Vanden Poel, E. van de Kerkhof, S. van Herwaarden, F. van Herwaarden, and A. Leenaers, Thermochim. Acta 522, 36 (2011).

32. F. Sadeghi, A. Ajji, and P. J. Carreau, J. Plast. Film Sheeting 21, 199 (2005).

33. P. Arora, and Z. (John) Zhang, Chem. Rev. 104, 4419 (2004).

34. R. W. Baker, Membrane Technology and Applications. (John Wiley \& Sons, Ltd., 2012).

35. S. S. Zhang, J. Power Sources 164, 351 (2007).

36. C. De Rosa, F. Auriemma, P. Vollaro, L. Resconi, S. Guidotti, and I. Camurati, Macromolecules 44, 540 (2011).

37. B. Lotz, Macromolecules 47, 7612 (2014).

38. R. Androsch, M. L. Di Lorenzo, C. Schick, and B. Wunderlich, Polymer 51, 4639 (2010).

39. F. Sadeghi, A. Ajji, and P. J. Carreau, J. Memb. Sci. 292, 62 (2007).

40. L. Caihong, W. Shuqiu, C. Qi, X. Ruijie, H. Bing, and S. Wenqiang, Polym. Int. 63, 584 (2013).

41. F. Sadeghi, A. Ajji, and P. J. Carreau, Polym. Eng. Sci. 47, 1170 (2007).

42. F. Sadeghi, A. Ajji, and P. J. Carreau, J. Polym. Sci. Part B Polym. Phys. 46, 148 (2008).

43. R. H. Somani, L. Yang, and B. S. Hsiao, Polymer 47, 5657 (2006).

44. S. H. Tabatabaei, P. J. Carreau, and A. Ajji, J. Memb. Sci. 325, 772 (2008).

45. P. Castejón, K. Habibi, A. Saffar, A. Ajji, A. B. Martínez, and D. Arencón, Polymers 10, 33 (2018).

46. S. H. Tabatabaei, P. J. Carreau, and A. Ajji, Polymer 50, 4228 (2009).

47. M. Xu, S. Zhang, J. Liang, H. Quan, J. Liu, H. Shi, D. Gao, and J. Liu, J. Appl. Polym. Sci. 131, 41100 (2014).

48. A. K. Doufas, A. J. McHugh, and C. Miller, J. Nonnewton. Fluid Mech. 92, 27 (2000).

49. A. K. Doufas, A. J. McHugh, C. Miller, and A. Immaneni, J. Nonnewton. Fluid Mech. 92, 81 (2000).

50. A. K. Doufas, and A. J. McHugh, J. Rheol. 45, 403 (2001).

51. A. K. Doufas, A. J. McHugh, and C. Miller, J. Nonnewton. Fluid Mech. 92, 27 (2000).

52. A. K. Doufas, and A. J. McHugh, J. Rheol. 45, 855 (2001).

53. J. S. Lee, D. M. Shin, H. W. Jung, and J. C. Hyun, J. Nonnewton. Fluid Mech. 130, 110 (2005).

54. D. M. Shin, J. S. Lee, H. W. Jung, and J. C. Hyun, Rheol. Acta 45, 575 (2006).

55. W. H. Kohler, and A. J. McHugh, Chem. Eng. Sci. 62, 2690 (2007).

56. W. H. Kohler, and A. J. McHugh, Polym. Eng. Sci. 48, 88 (2008).

57. D. Silagy, Y. Demay, and J. F. Agassant, Polym. Eng. Sci. 36, 2614 (1996).

58. A. I. Leonov, Rheol. Acta 15, 85 (1976).

59. M. Zatloukal, J. Nonnewton. Fluid Mech. 113, 209 (2003).

60. G. Lamberti, and G. Titomanlio, Polym. Bull. 46, 231 (2001). 
61. O. S. Narayanaswamy, J. Am. Ceram. Soc. 60, 1 (1977).

62. A. I. Leonov, E. H. Lipkina, E. D. Paskhin, and A. N. Prokunin, Rheol. Acta 15, 411 (1976).

63. A. I. Leonov, and A. N. Prokunin, Rheol. Acta 19, 393 (1980).

64. A. I. Leonov, and A. N. Prokunin, Rheol. Acta 22, 137 (1983).

65. M. Simhambhatla, and A. I. Leonov, Rheol. Acta 34, 259 (1995).

66. A. I. Leonov, Rheol. Ser. 8, 519 (1999).

67. T. Barborik, M. Zatloukal, and C. Tzoganakis, Int. J. Heat Mass Transf. 111, 1296 (2017).

68. G. Titomanlio, V. Speranza, and V. Brucato, Int. Polym. Process. 12, 45 (1997).

69. T. Barborik, and M. Zatloukal, J. Nonnewton. Fluid Mech. 255, 39 (2018).

70. M. Beaulne, and E. Mitsoulis, Int. Polym. Process. 14, 261 (1999).

71. R. Pivokonsky, M. Zatloukal, P. Filip, and C. Tzoganakis, J. Nonnewton. Fluid Mech. 156, 1 (2009).

72. S. S. Thete, P. Doshi, and H. V. Pol, J. Plast. Film Sheeting 33, 35 (2017).

73. R. Pantani, V. Speranza, and G. Titomanlio, J. Rheol. 59, 377 (2015).

74. R. Pantani, I. Coccorullo, V. Speranza, and G. Titomanlio, Prog. Polym. Sci. 30, 1185 (2005).

75. E. A. Jensen, and J. deC. Christiansen, J. Nonnewton. Fluid Mech. 148, 41 (2008).

76. T. Nagasawa, and Y. Shimomura, J. Polym. Sci. Polym. Phys. Ed. 12, 2291 (1974).

77. Y.-G. Zhou, W.-B. Wu, and L.-S. Turng, Jun Zou, J. Plast. Film Sheeting Print, (2015).

78. S. Wu, C. Lei, Q. Cai, R. Xu, B. Hu, W. Shi, and X. Peng, Polym. Bull. 71, 2205 (2014).

79. C. Xiande, X. Ruijie, X. Jiayi, L. Yuanfei, L. Caihong, and L. Liangbin, Polymer 94, 31 (2016).

80. T. Dobroth, and L. Erwin, Polym. Eng. Sci. 26, 462 (1986).

81. H. V. Pol, S. Banik, L. B. Azad, S. S. Thete, P. Doshi, and A. Lele, Rheol. Acta 53, 85 (2014).

82. M. Arroyo, M. A. Lopez-Manchado, and F. Avalos, Polymer 38, 5587 (1997). 


\section{TABLES}

Table 1. Basic characteristics for iPP T30G [9, 14, 17].

\begin{tabular}{|c|c|c|c|c|c|c|c|c|}
\hline$\underset{\left(\mathrm{g} \cdot \mathrm{mol}^{-1}\right)}{\mathbf{M n}_{\mathbf{n}}}$ & $\begin{array}{c}\mathbf{M}_{\mathbf{w}} \\
\left(\mathrm{g} \cdot \mathrm{mol}^{-1}\right)\end{array}$ & $\begin{array}{c}\text { PDI } \\
(1)\end{array}$ & $\begin{array}{c}\boldsymbol{\eta}^{\# \# \#} \\
\text { at } 220^{\circ} \mathrm{C} \\
(\mathrm{Pa} \cdot \mathrm{s})\end{array}$ & $\begin{array}{l}\text { Tacticity } \\
\text { (mmmm) }\end{array}$ & $\begin{array}{c}\mathbf{E}_{\mathbf{a}} \\
\left(\mathrm{kJ} \cdot \mathrm{mol}^{-1}\right)\end{array}$ & $\begin{array}{c}\mathbf{C}_{\mathbf{p}}^{\#} \\
\left(\mathrm{~J} \cdot \mathrm{Kg}^{-1} \cdot \mathrm{K}^{-1}\right)\end{array}$ & $\begin{array}{c}\mathbf{\rho p}^{\#} \\
\left(\mathrm{~kg} \cdot \mathrm{m}^{-3}\right)\end{array}$ & $\begin{array}{c}\Delta \mathbf{H}^{\# \#} \\
\left(\mathrm{~kJ} \cdot \mathrm{kg}^{-1}\right)\end{array}$ \\
\hline 75,000 & 481,000 & 6.4 & 7,402 & $87.6 \%$ & 40.092 & 2,200 & 920 & 209 \\
\hline
\end{tabular}

\# - Value taken from [81] as typical value for polyolefins.

\#\# - Value of crystallization latent heat taken from [82] as value for fully crystalline PP.

\#\#\# - Acquired by data digitalization technique from Figure 1 in [9].

Table 2. Modified Leonov model parameters for iPP T30G at $\mathrm{T}_{\mathrm{r}}=220^{\circ} \mathrm{C}$.

\begin{tabular}{|c|c|c|c|c|}
\hline$\lambda_{\mathbf{0}}(\mathrm{s})$ & $\mathbf{G}_{\mathbf{0}}(\mathrm{Pa})$ & $\xi_{(1)}$ & $\mathbf{v}(1)$ & $\boldsymbol{\beta}(1)$ \\
\hline 0.01 & 740,199 & 0 & 0.5 & 0.5 \\
\hline
\end{tabular}

Table 3. Summarization of processing conditions for iPP T30G taken from [10].

\begin{tabular}{|c|c|c|c|c|c|c|c|c|}
\hline $\begin{array}{c}\mathbf{\Omega} \\
(\mathrm{rpm})\end{array}$ & $\begin{array}{c}\mathbf{M F R} \\
\left(10^{-4} \mathrm{~kg} \cdot \mathrm{s}^{-1}\right)\end{array}$ & $\begin{array}{c}\mathbf{u} \mathbf{0} \\
\left(10^{-3} \mathrm{~m} \cdot \mathrm{s}^{-1}\right)\end{array}$ & $\begin{array}{c}\mathbf{u}(\mathbf{X}) \\
\left(10^{-3} \mathrm{~m} \cdot \mathrm{s}^{-1}\right)\end{array}$ & $\begin{array}{c}\mathbf{X} \\
(\mathrm{m})\end{array}$ & $\begin{array}{c}\text { TDIE } \\
\left({ }^{\circ} \mathrm{C}\right)\end{array}$ & $\begin{array}{c}\mathbf{2} \mathbf{L}_{0} \\
(\mathrm{~m})\end{array}$ & $\begin{array}{c}\mathbf{2 e 0} \\
\left(10^{-4} \mathrm{~m}\right)\end{array}$ & $\begin{array}{c}\mathbf{D R} \\
(1)\end{array}$ \\
\hline 20 & 1.26 & 1.68 & 58.3 & 0.4 & 200 & 0.2 & 5 & 34.7 \\
\hline
\end{tabular}

Ambient temperature, $\mathrm{T}_{\mathrm{a}}$, was kept at $23^{\circ} \mathrm{C}$ for all numerical studies.

Table 4. Crystallization kinetics parameters for iPP T30G taken from [60].

\begin{tabular}{|c|c|c|c|c|c|c|c|}
\hline $\begin{array}{c}\mathbf{X}_{\mathbf{e q}} \\
(1)\end{array}$ & $\begin{array}{c}\mathbf{n}_{\mathbf{c}} \\
(1)\end{array}$ & $\begin{array}{c}\mathbf{T}_{\mathbf{m}} \\
(\mathrm{K})\end{array}$ & $\begin{array}{c}\mathbf{E} \mathbf{c} / \mathbf{R} \\
(\mathrm{K})\end{array}$ & $\begin{array}{c}\mathbf{K 1} \\
\left(10^{69} \mathrm{~s}^{-1}\right)\end{array}$ & $\begin{array}{c}\mathbf{K 2} \\
(1)\end{array}$ & $\begin{array}{c}\mathbf{A}_{\mathbf{a t h}} \\
(1)\end{array}$ & $\begin{array}{c}\mathbf{B}_{\text {ath }} \\
\left(10^{-57} \mathrm{~s}\right)\end{array}$ \\
\hline 0.61 & 3 & 463.15 & 45,570 & 2.778 & 5.871 & 1.7721 & 3.448 \\
\hline
\end{tabular}

Table 5. Parameters used in Eq. 36 describing effect of crystallinity on elastic modulus G.

\begin{tabular}{|c|c|c|}
\hline $\mathbf{f}^{\#}(1)$ & $\mathbf{h}(1)$ & $\mathbf{m}^{\#}(1)$ \\
\hline 2,000 & $10^{-5}$ & 1.2 \\
\hline
\end{tabular}

\# - Value was taken from [9].

Table 6. Parameters used in Eq. 44 for the determination of critical crystallization border.

\begin{tabular}{|c|c|c|c|c|c|c|c|}
\hline $\boldsymbol{\alpha}_{\mathbf{k}}(1)$ & $\boldsymbol{\beta}_{\mathbf{k}}(1)$ & $\boldsymbol{\gamma}_{\mathbf{k}}(1)$ & $\boldsymbol{\delta}_{\mathbf{k}}(1)$ & $\boldsymbol{\alpha}_{\mathbf{q}}(1)$ & $\boldsymbol{\beta}_{\mathbf{q}}(1)$ & $\boldsymbol{\gamma}_{\mathbf{q}}(1)$ & $\boldsymbol{\delta}_{\mathbf{q}}(1)$ \\
\hline-0.0058 & 0.4677 & 0.0072 & -1.1269 & 0.0003 & -1.0809 & 0.0086 & -0.2473 \\
\hline
\end{tabular}


Table 7. Parameters used in Eq. 44 for the determination of isothermality boundary.

\begin{tabular}{|c|c|c|c|c|c|c|c|}
\hline $\boldsymbol{\alpha}_{\mathbf{k}}(1)$ & $\boldsymbol{\beta}_{\mathbf{k}}(1)$ & $\boldsymbol{\gamma}_{\mathbf{k}}(1)$ & $\boldsymbol{\delta}_{\mathbf{k}}(1)$ & $\boldsymbol{\alpha}_{\mathbf{q}}(1)$ & $\boldsymbol{\beta}_{\mathbf{q}}(1)$ & $\boldsymbol{\gamma}_{\mathbf{q}}(1)$ & $\boldsymbol{\delta}_{\mathbf{q}}(1)$ \\
\hline 0.0009 & 0.1900 & -0.0004 & 0.1554 & -0.0002 & -0.8144 & -0.0002 & 0.9799 \\
\hline
\end{tabular}




\section{FIGURES}

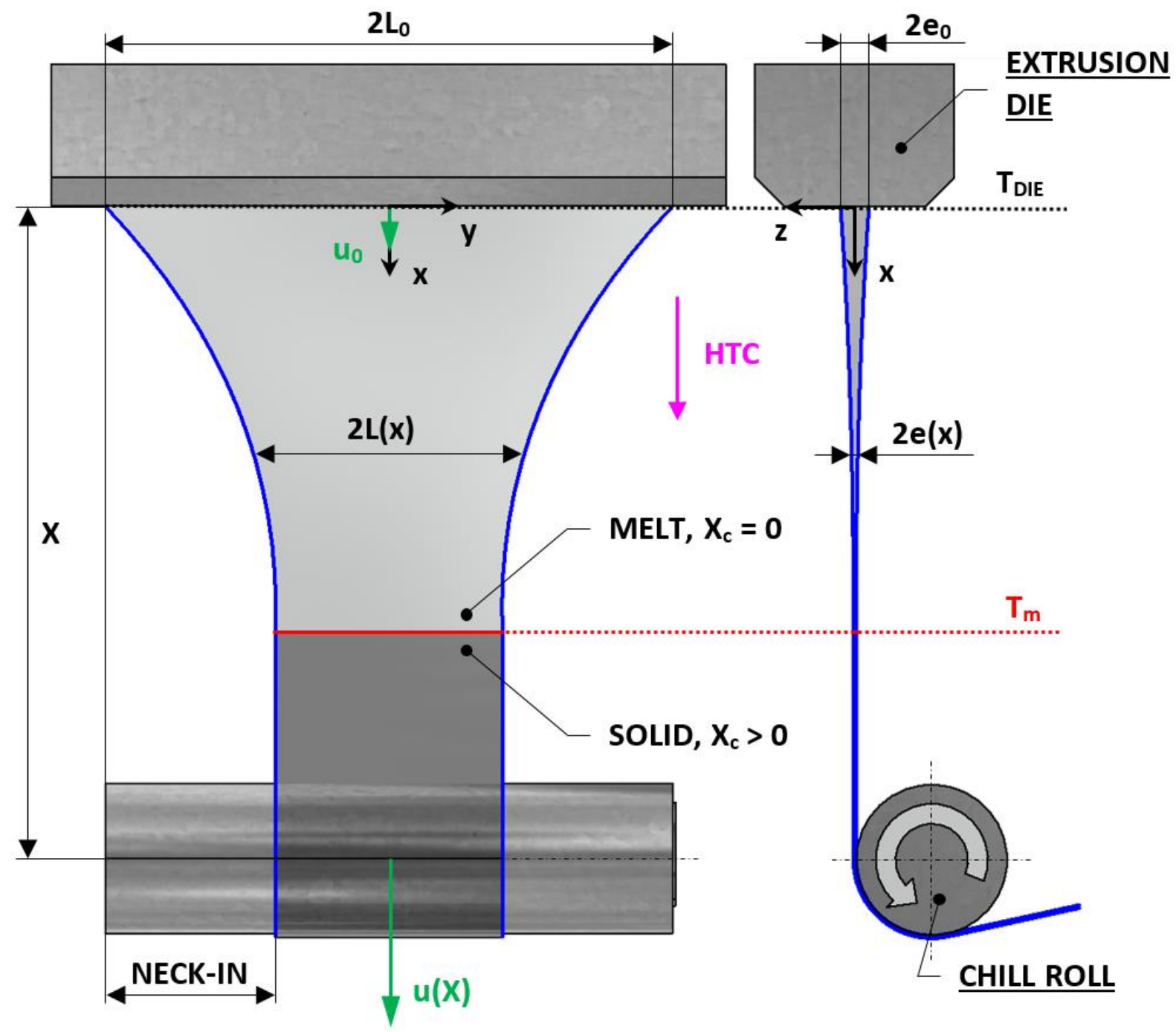

Figure 1. Schematic illustration of extrusion film casting process. 


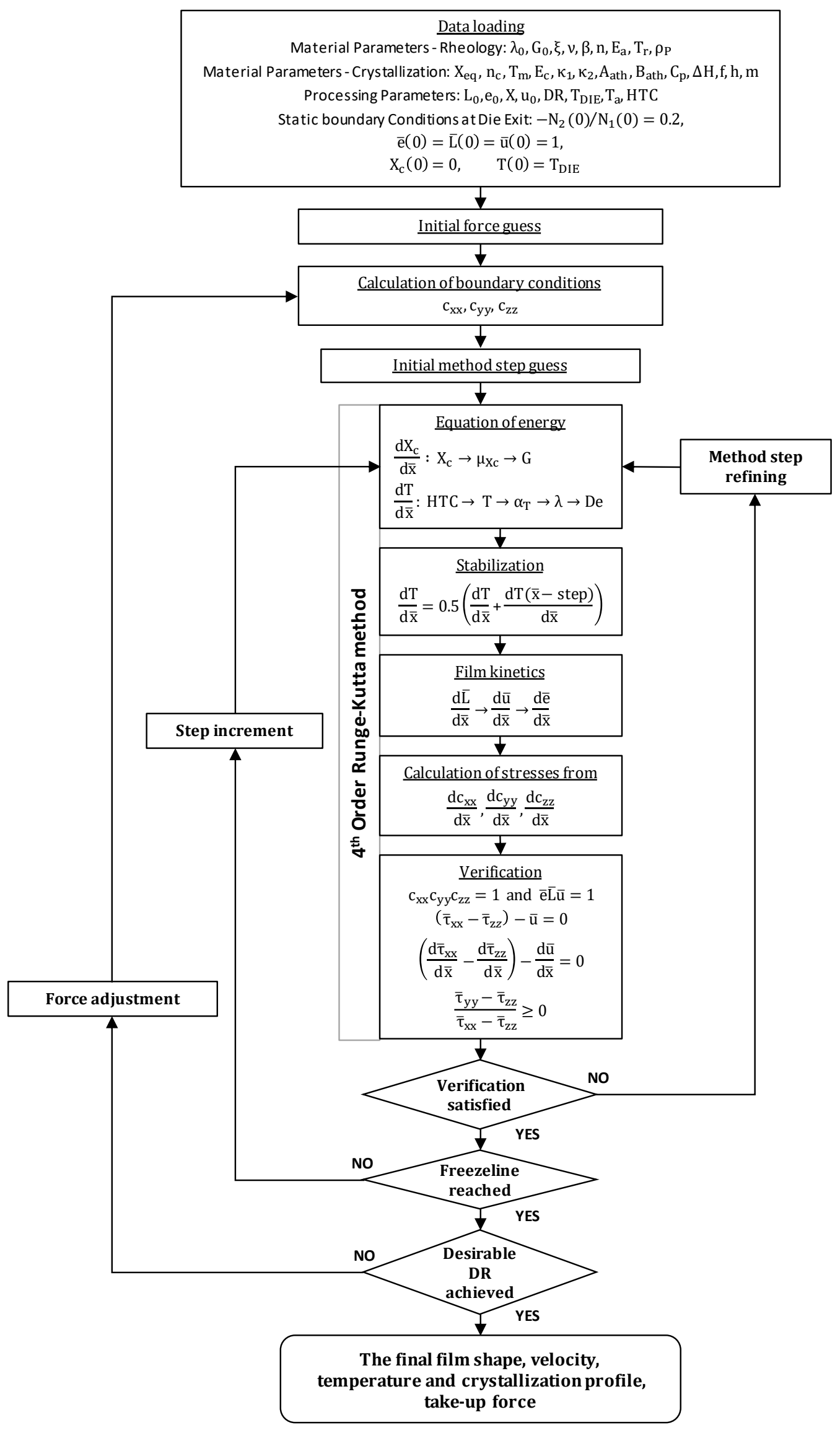

Figure 2. The flow diagram of implemented numerical scheme to solve the proposed film casting model. 
3a)

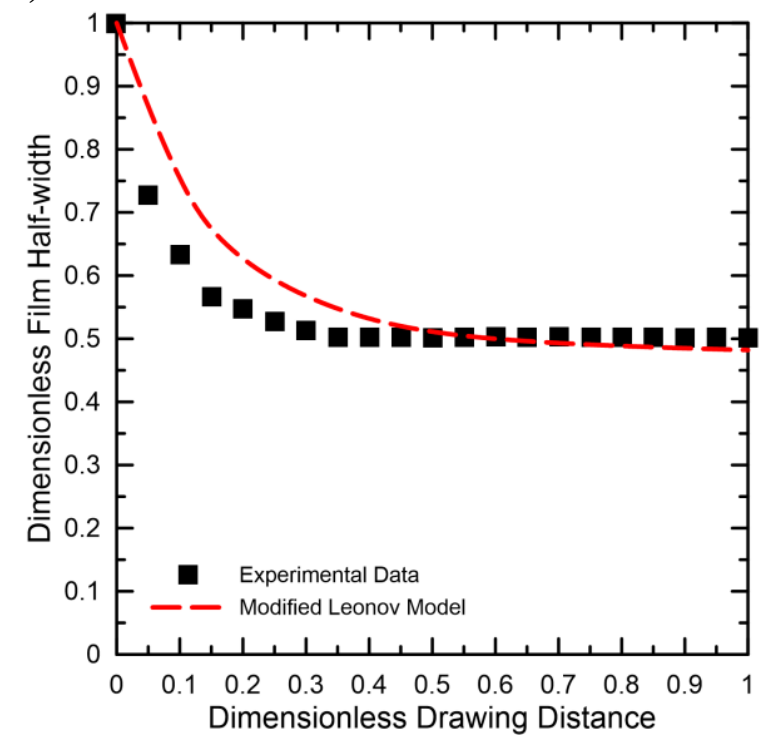

3c)

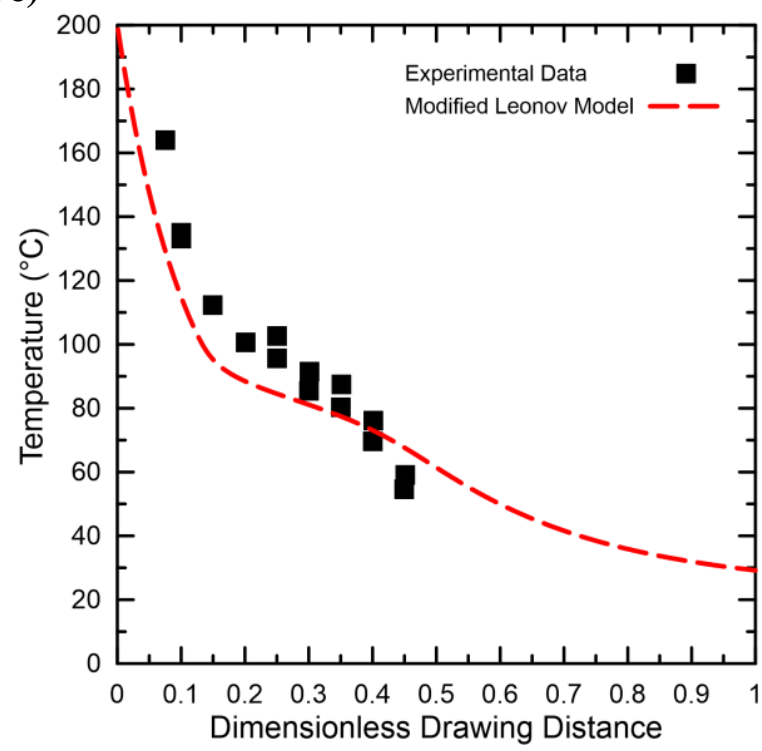

3b)

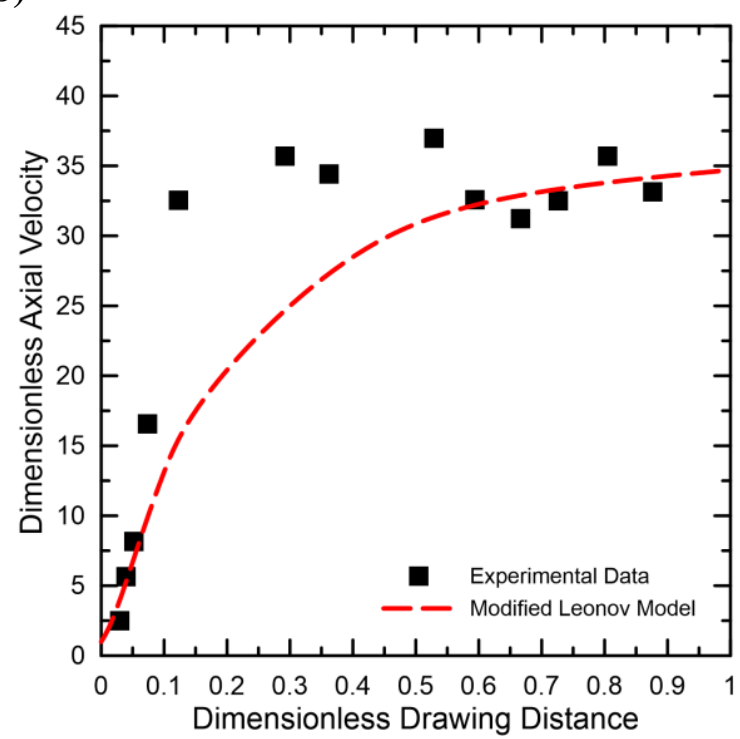

3d)

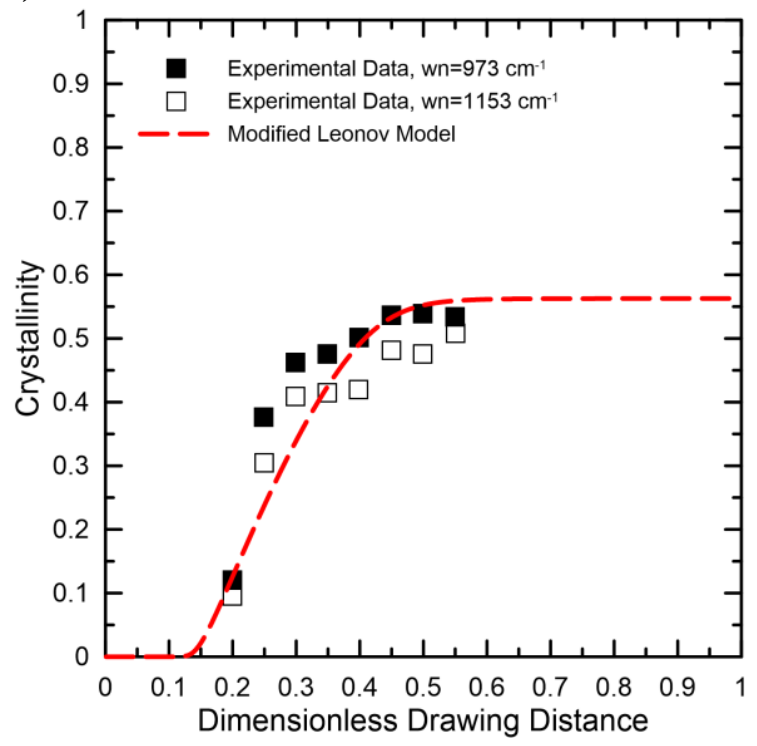

Figure 3. Comparison between experimental data for iPP $\mathrm{T} 30 \mathrm{G}\left(\mathrm{T}_{\mathrm{DIE}}=200^{\circ} \mathrm{C}\right)$ and given processing conditions $\left(\mathrm{De}=6 \cdot 10^{-4}, \mathrm{DR}=34.7, \mathrm{X}=0.4 \mathrm{~m}\right)$ taken both from [10] and model predictions for dimensionless drawing distance variables considering constant heat transfer coefficient, HTC $=16 \mathrm{~J} \cdot \mathrm{s}^{-1} \cdot \mathrm{K}^{-1} \cdot \mathrm{m}^{-2}$. (a) Dimensionless Final Half-width, (b) Dimensionless Axial Velocity, (c) Temperature, (d) Crystallinity. 


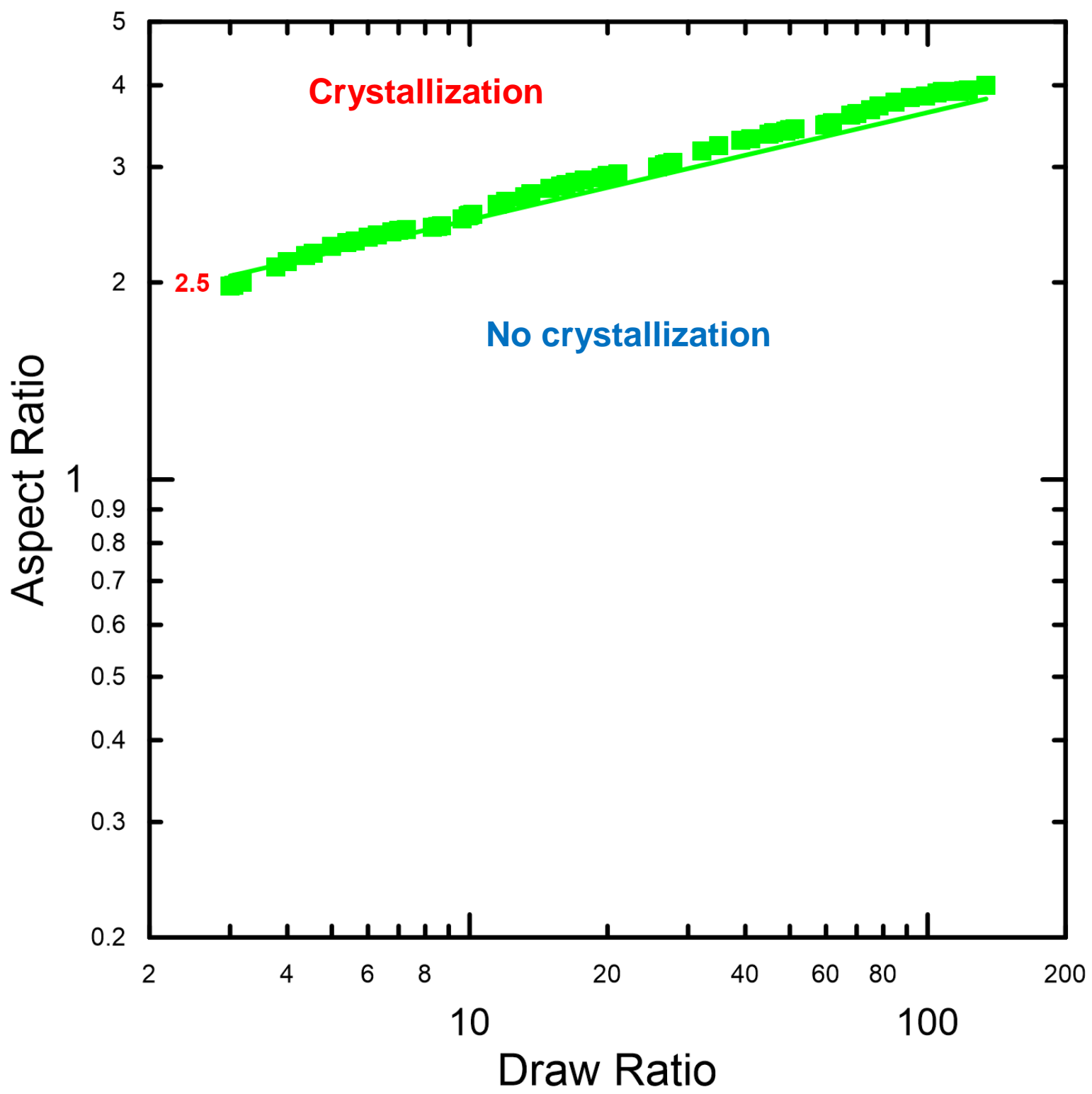

Figure 4. Predicted processing window for production of linear iPP films with (area above the border symbols) and without (area below the border symbols) the crystallized phase for given heat transfer coefficient $\left(\mathrm{HTC}=2.5 \mathrm{~J} \cdot \mathrm{s}^{-1} \cdot \mathrm{K}^{-1} \cdot \mathrm{m}^{-2}\right)$ and melt temperature at the die exit $\left(\mathrm{T}_{\mathrm{DIE}}=200^{\circ} \mathrm{C}\right)$. 


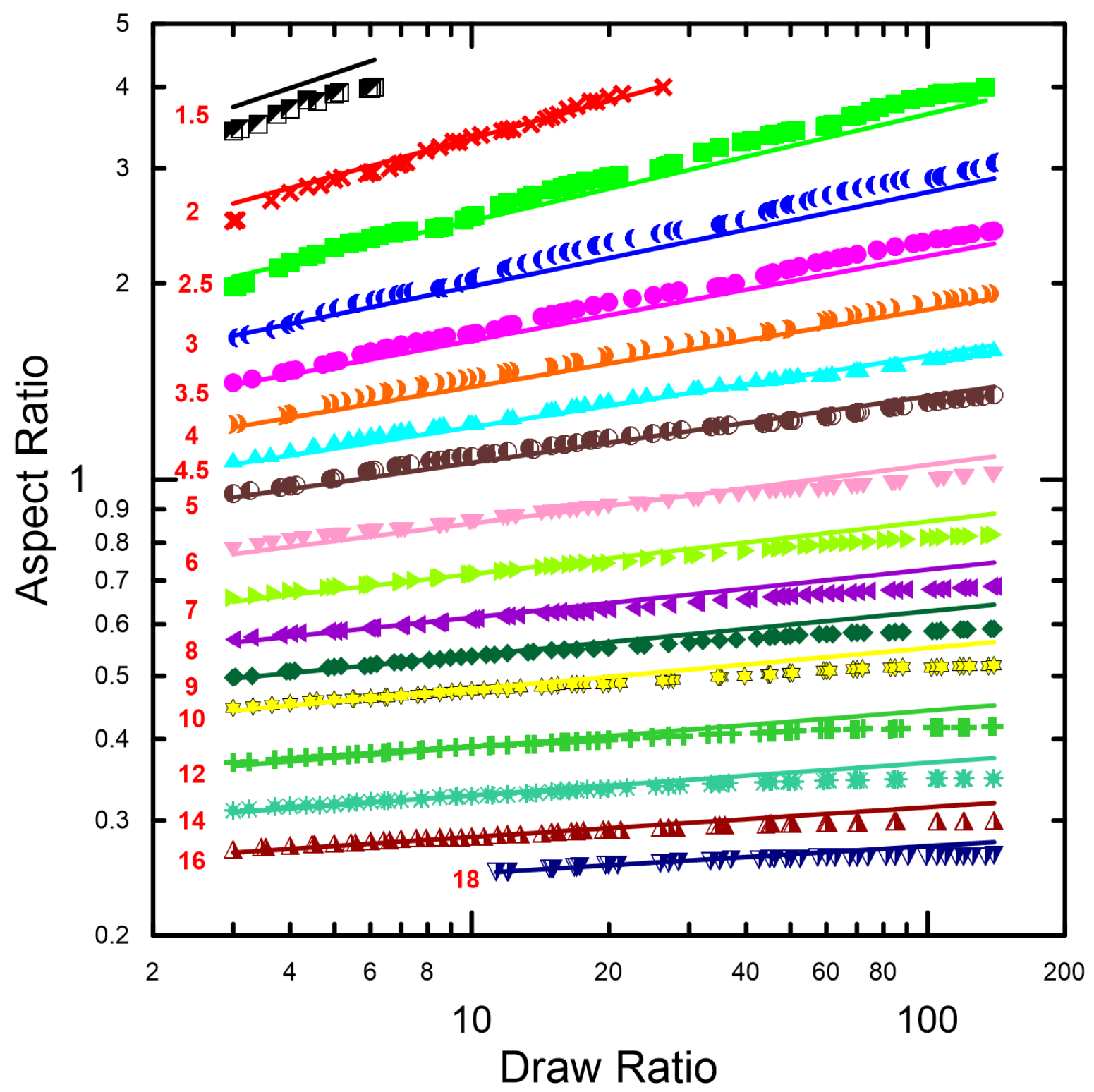

Figure 5. Effect of draw ratio, heat transfer coefficient (see numbers in $\mathrm{J} \cdot \mathrm{s}^{-1} \cdot \mathrm{K}^{-1} \cdot \mathrm{m}^{-2}$ provided at each data set) and melt temperature at the die exit, $\mathrm{T}_{\mathrm{DIE}}=200^{\circ} \mathrm{C}$, on the aspect ratio, at which crystallization in linear iPP film starts to occur (border predicted by a numerical model is given by the symbols, lines represent analytical approximation given by Eq. 44). 


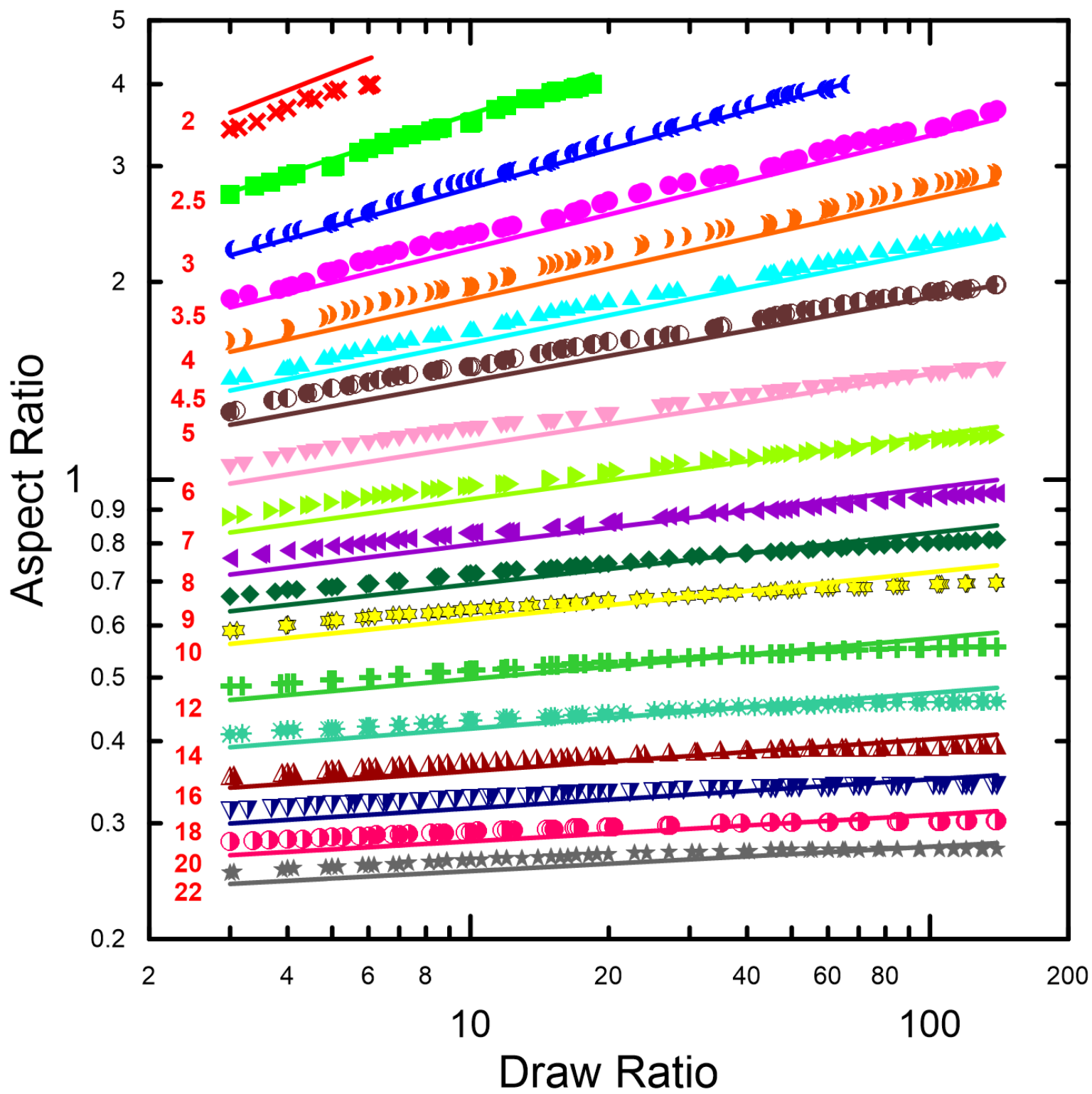

Figure 6. Effect of draw ratio, heat transfer coefficient (see numbers in $\mathrm{J} \cdot \mathrm{s}^{-1} \cdot \mathrm{K}^{-1} \cdot \mathrm{m}^{-2}$ provided at each data set) and melt temperature at the die exit, $\mathrm{T}_{\mathrm{DIE}}=225^{\circ} \mathrm{C}$, on the aspect ratio, at which crystallization in linear iPP film starts to occur (border predicted by a numerical model is given by the symbols, lines represent analytical approximation given by Eq. 44). 


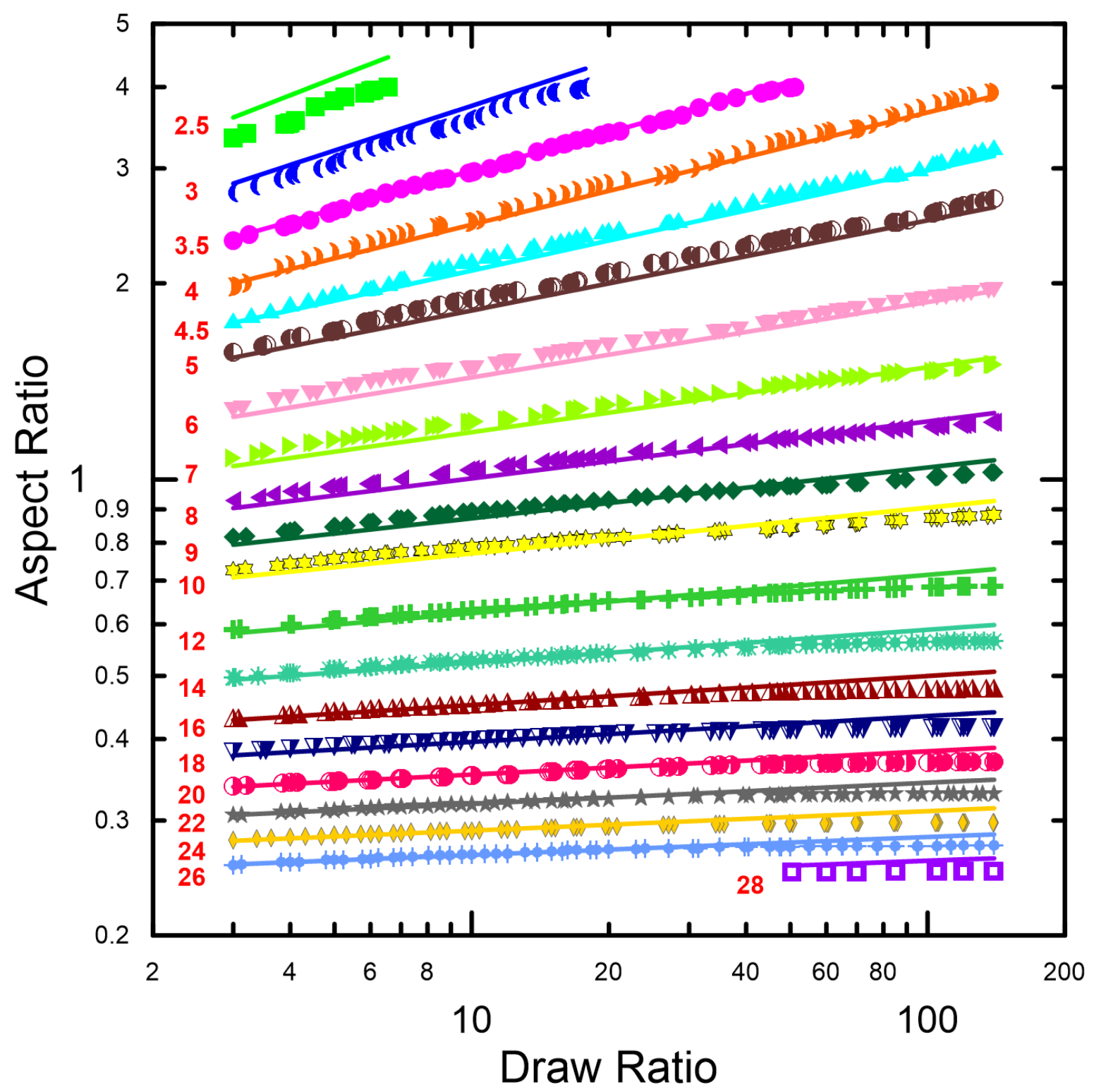

Figure 7. Effect of draw ratio, heat transfer coefficient (see numbers in $\mathrm{J} \cdot \mathrm{s}^{-1} \cdot \mathrm{K}^{-1} \cdot \mathrm{m}^{-2}$ provided at each data set) and melt temperature at the die exit, $\mathrm{T}_{\mathrm{DIE}}=250^{\circ} \mathrm{C}$, on the aspect ratio, at which crystallization in linear iPP film starts to occur (border predicted by a numerical model is given by the symbols, lines represent analytical approximation given by Eq. 44). 


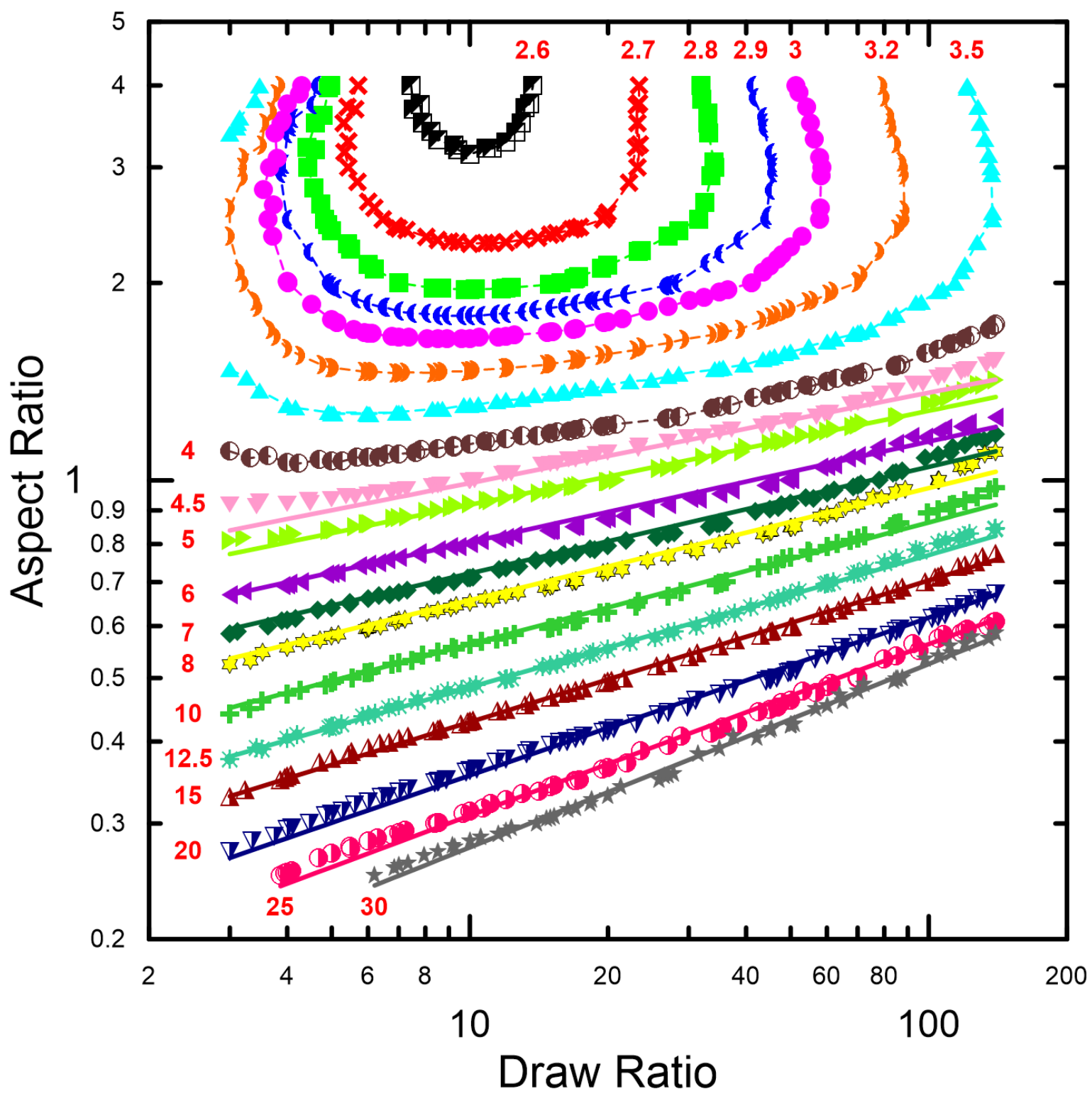

Figure 8. Effect of draw ratio and heat transfer coefficient (see numbers in $\mathrm{J} \cdot \mathrm{s}^{-1} \cdot \mathrm{K}^{-1} \cdot \mathrm{m}^{-2}$ provided at each data set) on the critical aspect ratio below which the non-isothermal and isothermal calculations gives for linear iPP practically the same neck-in value (considering melt temperature at the die exit equal to $200^{\circ} \mathrm{C}$, border predicted by a numerical model is given by the symbols, lines represent analytical approximation given by Eq. Error! Reference source not found.). 


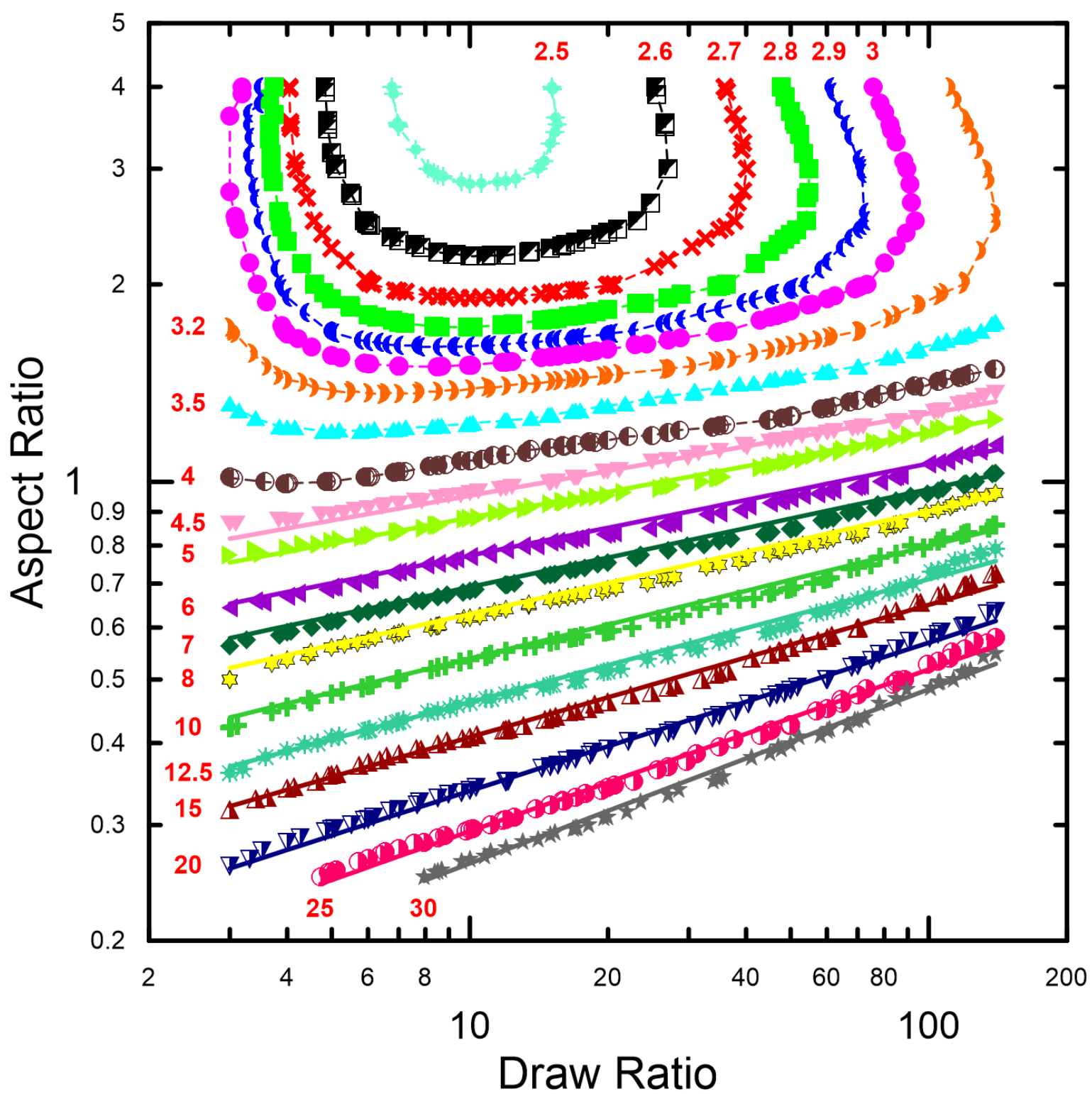

Figure 9. Effect of draw ratio and heat transfer coefficient (see numbers in $\mathrm{J} \cdot \mathrm{s}^{-1} \cdot \mathrm{K}^{-1} \cdot \mathrm{m}^{-2}$ provided at each data set) on the critical aspect ratio below which the non-isothermal and isothermal calculations gives for linear iPP practically the same neck-in value (considering melt temperature at the die exit equal to $225^{\circ} \mathrm{C}$, border predicted by a numerical model is given by the symbols, lines represent analytical approximation given by Eq. Error! Reference source not found.). 


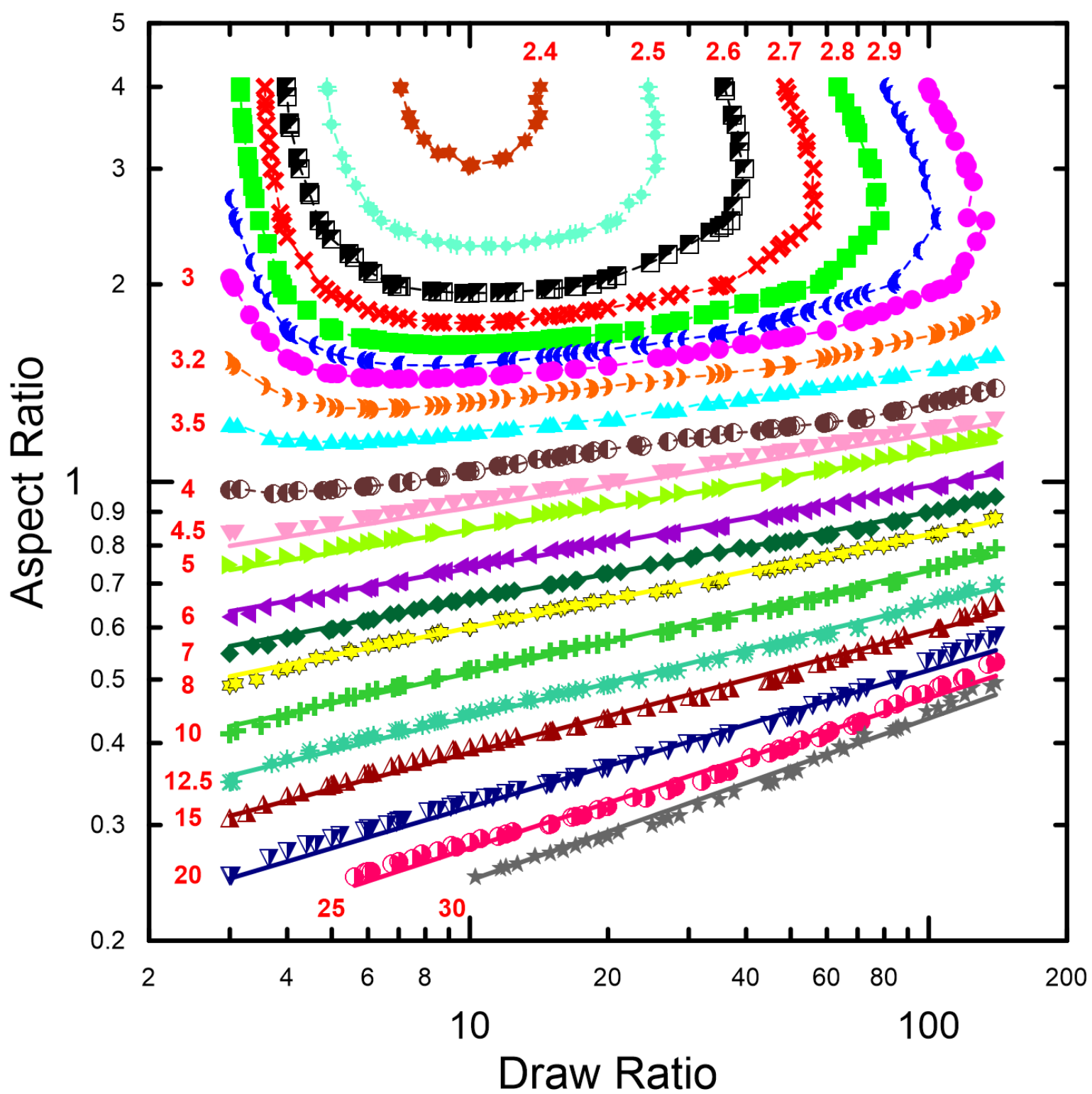

Figure 10. Effect of draw ratio and heat transfer coefficient (see numbers in $\mathrm{J} \cdot \mathrm{s}^{-1} \cdot \mathrm{K}^{-1} \cdot \mathrm{m}^{-2}$ provided at each data set) on the critical aspect ratio below which the non-isothermal and isothermal calculations gives for linear iPP practically the same neck-in value (considering melt temperature at the die exit equal to $250^{\circ} \mathrm{C}$, border predicted by a numerical model is given by the symbols, lines represent analytical approximation given by Eq. Error! Reference source not found.). 


\begin{tabular}{|c|c|c|c|c|c|c|c|c|c|c|c|}
\hline $\begin{array}{l}-- \\
--\end{array}$ & $\begin{array}{l}A=0.01 \\
A=0.05\end{array}$ & $\begin{array}{l}-- \\
--\end{array}$ & $\begin{array}{l}A=0.1 \\
A=0.25\end{array}$ & $\begin{array}{l}-- \\
--\end{array}$ & $\begin{array}{l}A=0.5 \\
A=0.75\end{array}$ & $\begin{array}{l}-- \\
--\end{array}$ & $\begin{array}{l}A=1 \\
A=2\end{array}$ & -- & $\begin{array}{l}A=3 \\
A=4\end{array}$ & $\begin{array}{l}-A= \\
--A=\end{array}$ & $\begin{array}{l}=6-1-A=10 \\
=8\end{array}$ \\
\hline
\end{tabular}
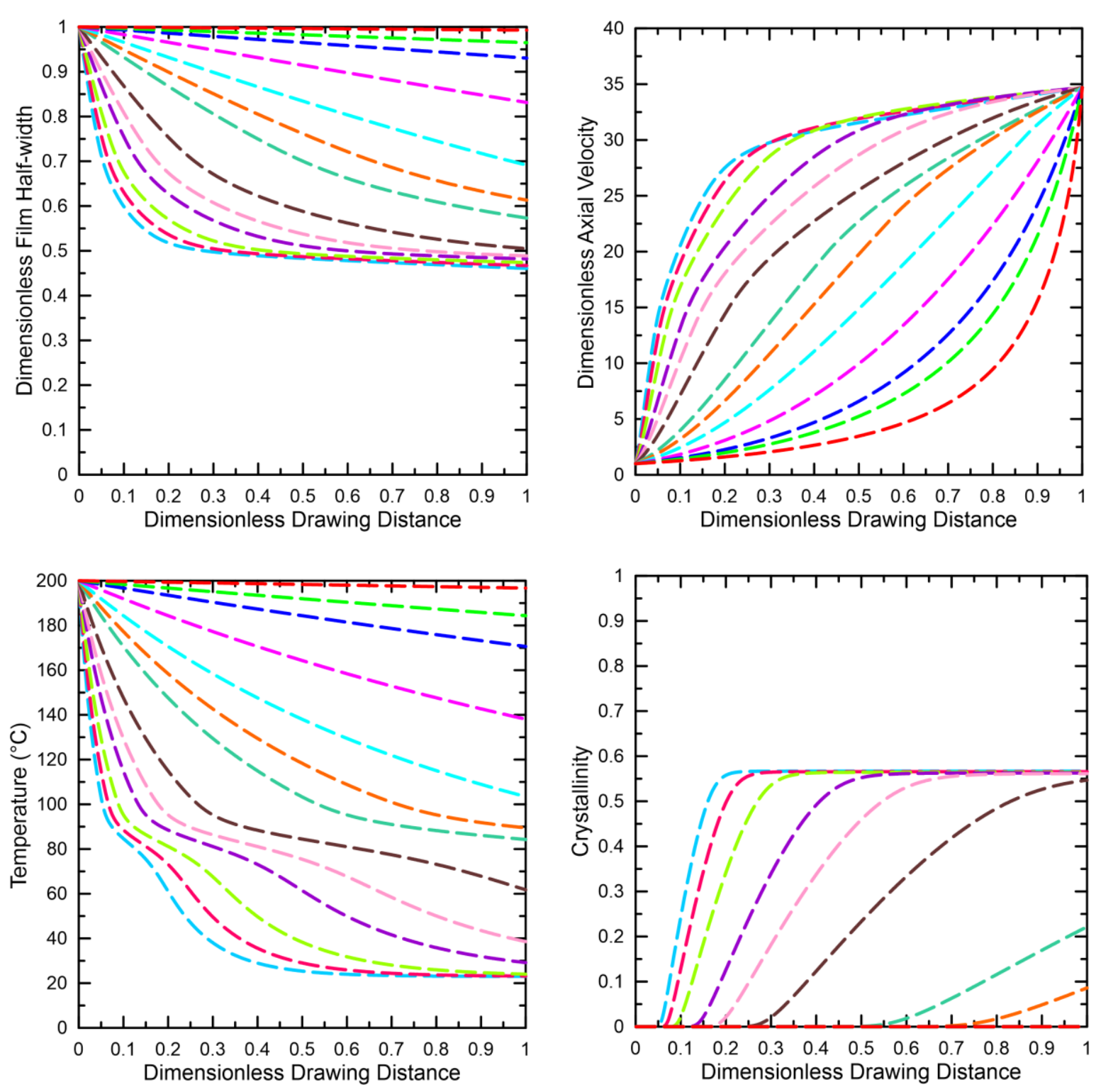

Figure 11. Effect of aspect ratio (changed via drawing distance, $\mathrm{X}$ ) on dimensionless-drawingdistance dependent dimensionless film half-width (top, left), dimensionless axial velocity (top, right), temperature (bottom, left) and film crystallinity for the linear iPP and the reference flow conditions $\left(\mathrm{HTC}=16 \mathrm{~J} \cdot \mathrm{s}^{-1} \cdot \mathrm{K}^{-1} \cdot \mathrm{m}^{-2}, \mathrm{~T}_{\mathrm{DIE}}=200^{\circ} \mathrm{C}, \mathrm{DR}=34.7\right)$. 


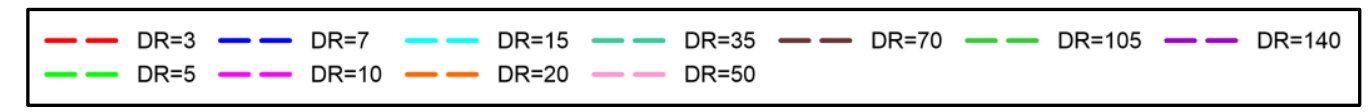
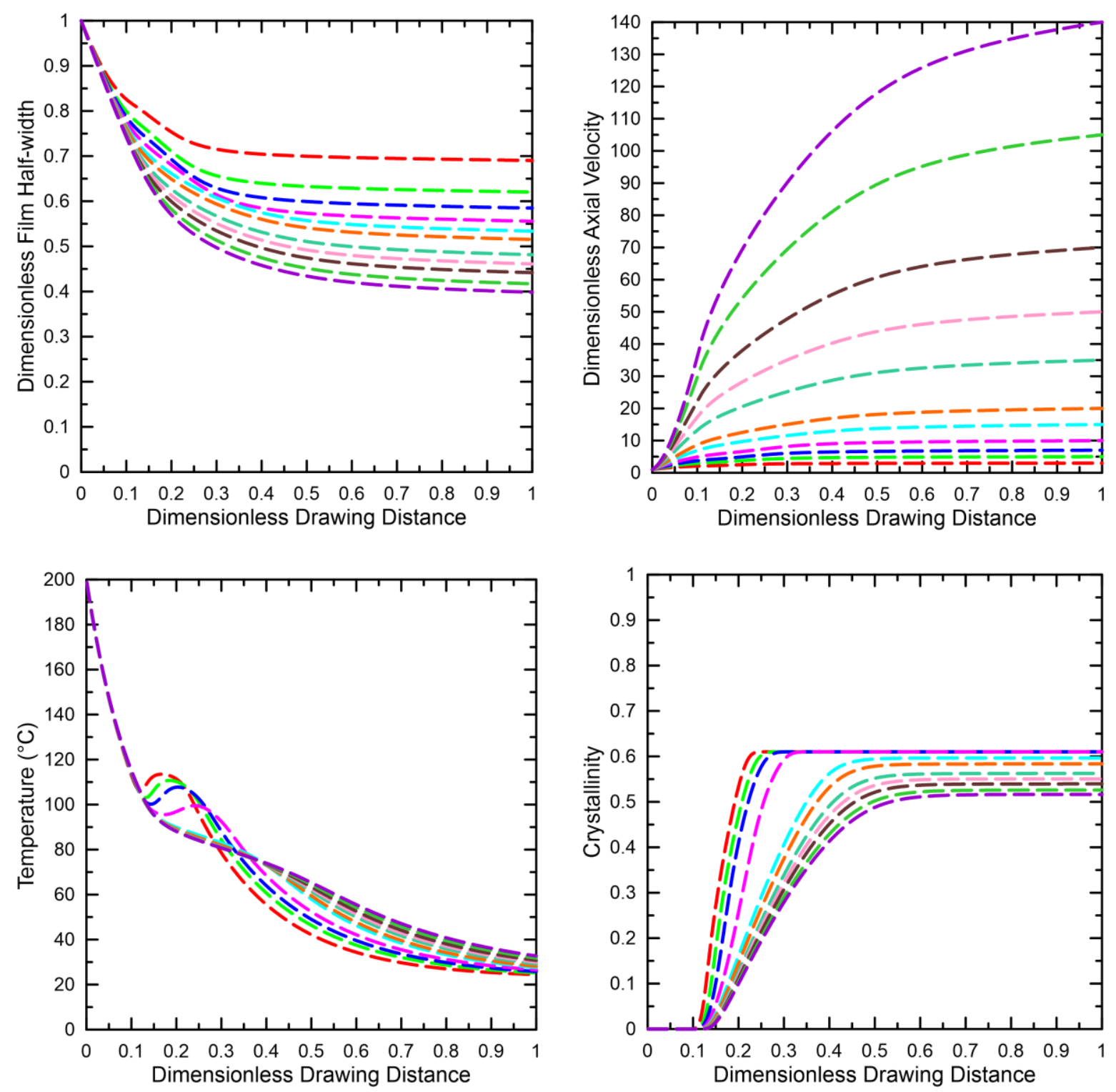

Figure 12. Effect of draw ratio on dimensionless-drawing-distance dependent dimensionless film half-width (top, left), dimensionless axial velocity (top, right), temperature (bottom, left) and film crystallinity for the linear iPP and the reference flow conditions $\left(A=4, H T C=16 \mathrm{~J} \cdot \mathrm{s}^{-}\right.$ $\left.{ }^{1} \cdot \mathrm{K}^{-1} \cdot \mathrm{m}^{-2}, \mathrm{~T}_{\mathrm{DIE}}=200^{\circ} \mathrm{C}\right)$. 


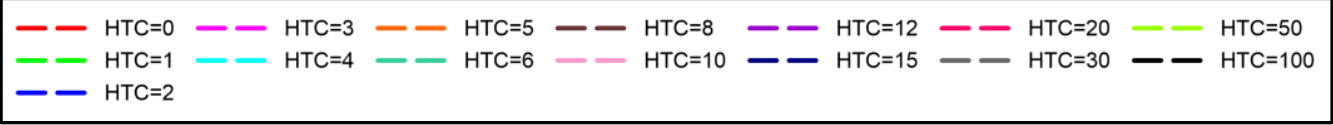
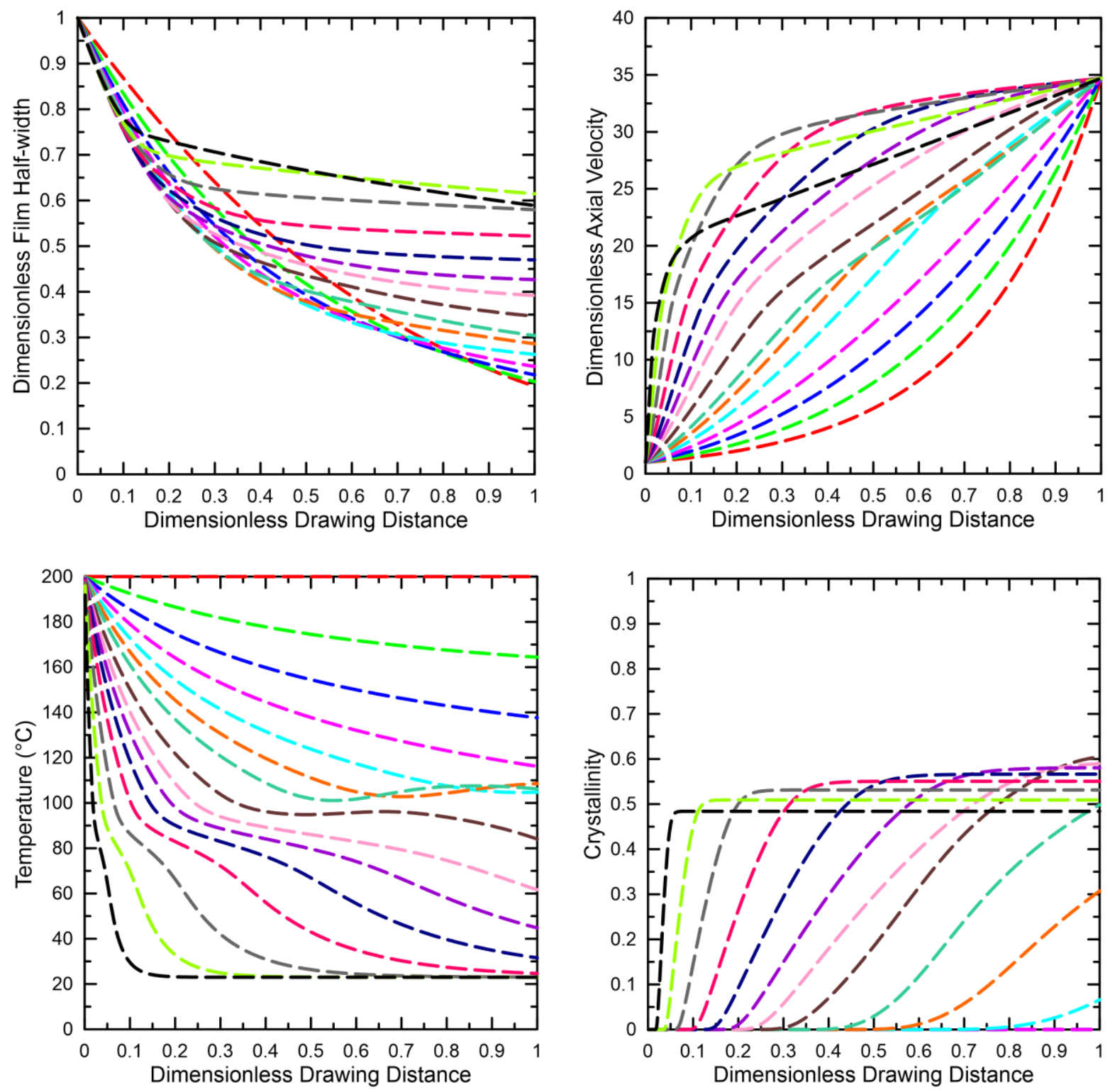

Figure 13. Effect of heat transfer coefficient on dimensionless-drawing-distance dependent dimensionless film half-width (top, left), dimensionless axial velocity (top, right), temperature (bottom, left) and film crystallinity for the linear iPP and the reference flow conditions $(\mathrm{A}=4$,

$\mathrm{DR}=34.7, \mathrm{~T}_{\mathrm{DIE}}=200^{\circ} \mathrm{C}$ ). 

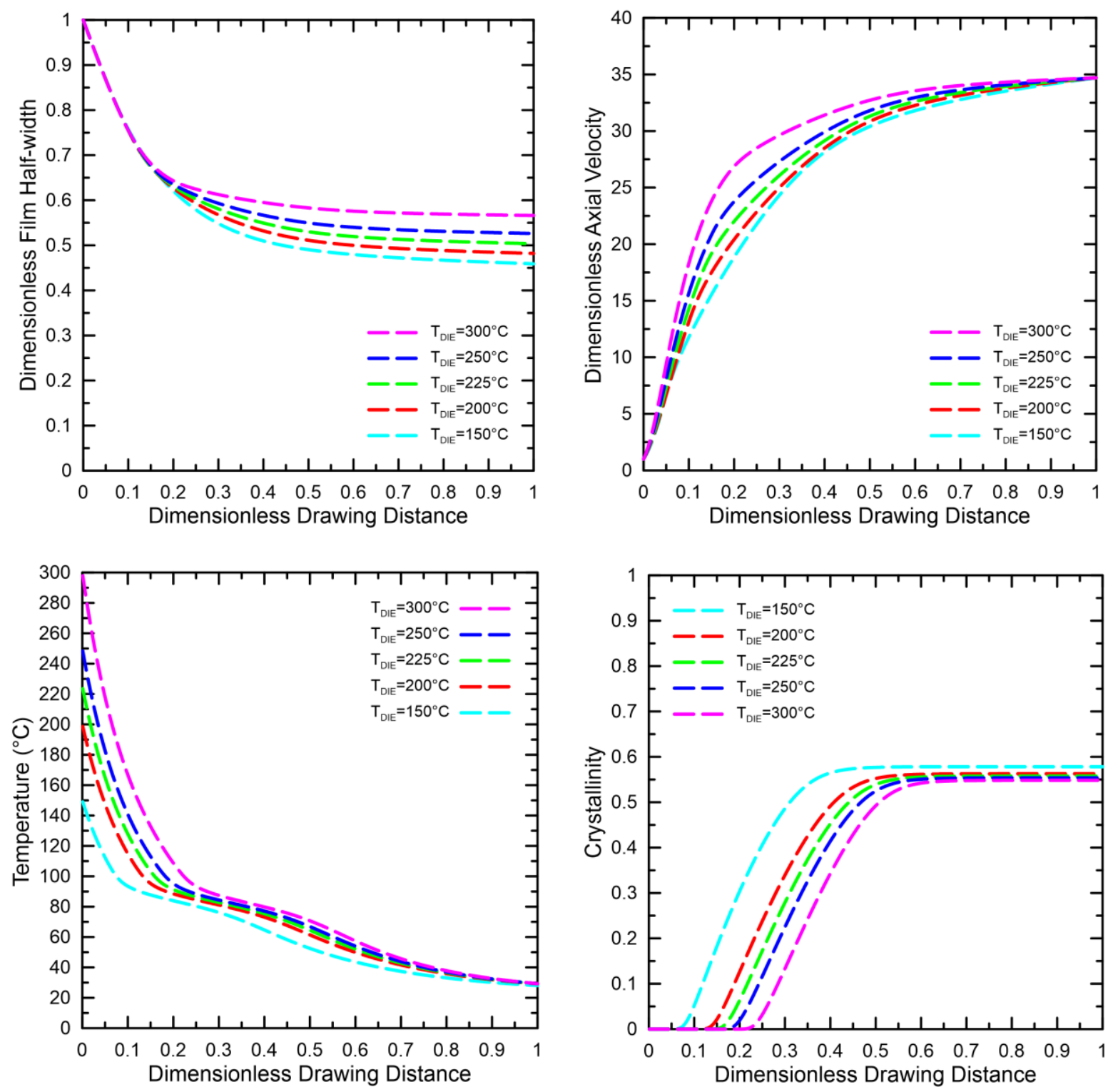

Figure 14. Effect of melt temperature at the die exit on dimensionless-drawing-distance dependent dimensionless film half-width (top, left), dimensionless axial velocity (top, right), temperature (bottom, left) and film crystallinity for the linear iPP and the reference flow conditions $\left(\mathrm{A}=4, \mathrm{DR}=34.7, \mathrm{HTC}=16 \mathrm{~J} \cdot \mathrm{s}^{-1} \cdot \mathrm{K}^{-1} \cdot \mathrm{m}^{-2}\right)$. 